\title{
Establishing The Relative Competitiveness Of South African Banking Shares: A Kalman Filter Approach
}

Chris van Heerden, North West University, South Africa

Gary van Vuuren, North West University, South Africa

\begin{abstract}
It is argued that the Basel III Accord will undermine the ROE of South African banks, and with the downgrading of South African banks during August 2014, will force investors to revaluate South African banking shares as attractive investment options. However, results from the Sharpe and Omega ratios, based on returns forecast using the Kalman filter, accentuate the likelihood that the South African industry can still be expected to be a competitive and feasible investment option after the downgrade. Evidence suggests that Capitec Bank Holdings Limited and Standard Bank Group Limited will perform the worst of all the South African banks, whereas FirstRand Limited, Investec Limited, and Barclays African Group will exhibit more promise in the future, outperforming world indices, such as the DAX, FTSE 100 and the S\&P 500.
\end{abstract}

Keywords: Kalman Filter; Omega Ratio; Sharpe Ratio; South African Banks

\section{INTRODUCTION}

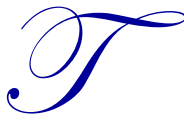

he 2007-2009 global financial crisis reinforced the importance of revaluating bank competition (GFD, 2013), especially if the competitive edge is associated with financial innovations, like sub-prime lending, which is considered as one of the contributors to the financial crisis (Bianco, 2008; BlundellWignall, Atkinson \& Lee, 2008). New policies and regulations have been developed to address the sources of the financial crisis (see for example BIS, 2011), though regulators and policymakers should be wary of restricting future bank competition completely in an attempt to stabilise the financial system. In addition, by limiting competition in the banking industry additional pressure will be put on profitability and bank performance (GFD, 2013). For example, the Basel Committee on Banking Supervision (BCBS) attempted to strengthen the global capital and liquidity rules by introducing the Basel III Accord (BIS, 2011). Although this Accord will enhance the financial landscape in terms of complexity, interdependency, supervision and dynamism in order to contain further economic failures, this Accord can have a significant impact on banks (KPMG, 2011). This may for instance initiate a higher demand for long-term funding, caused by the introduction of the Net Stable Funding ratio and the Liquidity Coverage ratio (Härle, Lüders, Pepanides, Pfetsch, Poppensieker \& Stegemann, 2010; BIS, 2011); a decrease in competition, due to weaker banks failing to acquire the new required level of regulatory capital; and lower profitability and Returns on Equity (ROE) levels, due to higher pressure on operating capacity and margins (KPMG, 2011). These lower profitability and ROE levels will eventually spill over to the investor, which will have a negative influence on the future sentiment of investing in banking shares.

Also from a South African perspective, the four major South African banks were downgraded to a Baal, based on Moody's evaluation of the South African Reserve Bank's (SARB) past actions. It was argued that there is a lower likelihood of systemic support by the SARB, as demonstrated with the bail-out of African Bank, which caused Moody's to question the South African banking industry's credit health (Fin24, 2014). This announcement caused the JSE Banking index to decrease by approximately $1.2 \%$, which accentuated the level of uncertainty that investors have to confront (Fin24, 2014a). These events prompted an inquiry to determine whether the South African banking industry may still be considered competitive and a stable investment choice for both domestic and foreign investors. 
The goal of this paper is to determine whether the South African banking industry remains competitive in terms of share performance. The risk-adjusted performance of nine listed South African banks was evaluated over pre-, during, and post-financial crisis periods, respectively. This was accomplished by consulting the Sharpe (Sharpe, 1966) and Omega ratios (Keating \& Shadwick, 2002). However, these ratios are still fallible as they are still backward-looking (Togher \& Barsbay, 2007). Also, with Moody's actions escalating the level of uncertainty during August 2014, with the downgrade of the four major South African banks and of Capitec Limited (Fin24, 2014, 2014b), necessitates the use of an additional performance measure that has the capacity to forecast performance.

This performance measure entails the Kalman filter (Kalman, 1960), which is known to be a "linear, discrete time, finite dimensional time-varying system" that has the ability to evaluate "the state estimate which minimises the mean-square error" (Ribeiro, 2004:2). This implies that the Kalman filter is an estimator with the ability to estimate the instantaneous state of a linear dynamic system which is perturbed by white noise, where the resulting estimator is also statistically optimal with respect to any quadratic function of the estimation error (Grewal \& Andrews, 2001). In other words, by applying only historical information, the dynamic quality of the state model allows the Kalman filter to adjust rapidly to changes in the market and allows real time updates to fit (Punales, 2011). The Kalman filter also supports estimations of both past, present and future states, even with the precise nature of the modelled system being unknown (Welch \& Bishop, 2006). The assumptions used in the formulation of the Kalman filter are more robust compared to the assumptions of constant exposure employed in regression analyses (Tsay, 2010). This makes the Kalman filter a more desirable model, where it superior estimation abilities have also been proven by several studies, such as Brooks, Faff and McKenzie (1998) and Faff, Hillier and Hillier (2000). Also, based on the respectable in-sample and out-of-sample forecast errors found by Brooks, Faff and McKenzie (1998), this paper will use the Kalmin filter to generate an out-of-sample forecast of the returns under investigation, which will enable the Sharpe and Omega ratios to establish if the South African banking industry can still be expected to be a feasible investment option after the downgrade.

To accomplish these objectives this paper commences with a discussion on preliminary findings, which serves as a motivation for investigating the performance of the South African banking industry (Section 2). Section 3 provides an overview of the development of the South African bank industry. This is followed by a brief discussion of risk-adjusted performance measures and methodology (Section 4), and a discussion on the reported results in Section 5. Section 6 provides concluding remarks and recommendations for further work.

\section{PRELIMINARY FINDINGS - MOTIVATION FOR A FURTHER INVESTIGATION}

The implementation of Basel III can lead to lower profitability and Returns on Equity (ROE) levels, due to higher pressure on operating capacity and margins (KPMG, 2011). To emphasise this statement from a South African perspective, Table 1 reports the ROE of the nine South African banks over the period 2003 to 2013, respectively, which are also listed on the Johannesburg Stock Exchange (JSE). These nine banks comprise out of Barclays African Group (BGA), FirstRand Limited (FSR), Investec Limited (INL), Nedbank Group Limited (NED), the Standard Bank Group Limited (SBK), African Bank Investments Limited (ABL), Capitec Bank Holdings Limited (CPI), Grindrod Limited (GND), and Sasfin Holdings Limited (SFN). The results reported in Table 1 and Figure 1 justifity the fact that the global financial crisis had a significant effect on the performance of these banks. Although the yearly average illustrated a significant increase in the ROE from 2003 to 2006, it decreased substantially from 2007 to 2013 (21.8\%), representing a decrease in profits that were distributed to shareholders (see Figure 1). The four major South African banks (BGA, FSR, NED \& SBK), which represent $84 \%$ of the total banking assets (The Banking Association of South Africa, 2012), also failed to provide the highest ROE over the period under investigation. GND exhibited the highest average ROE (28.4\%), followed by FSR (24.3\%), ABL (23.0\%), SFN (21.4\%) and BGA (19.2\%), respectively. However, note that the ROE of ABL decreased significantly during 2013, as earnings declined substantially due to its unsecured lending activities (Fin24, 2013), and will continue to drop as the South African Reserve bank had to bail out ABL, which includes Ellerines, in an attempt to restore the confidence in the South African banking industry and bond market. 
Table 1: Annual ROE (\%) Of The Nine JSE Listed South African Banks: 2003-2013

\begin{tabular}{|c|c|c|c|c|c|c|c|c|c|c|}
\hline Date & BGA & FSR & INL & NED & SBK & ABL & CPI & GND & SFN & $\begin{array}{c}\text { Average per } \\
\text { Annum }\end{array}$ \\
\hline 2003 & 20.11 & 20.61 & -10.70 & -13.74 & 22.14 & 23.66 & 7.78 & 38.40 & 12.10 & 13.48 \\
\hline 2004 & 23.28 & 24.18 & 10.08 & 5.38 & 26.61 & 28.63 & 10.60 & 65.25 & 26.48 & 24.50 \\
\hline 2005 & 22.16 & 30.12 & 15.62 & 17.06 & 25.61 & 64.45 & 14.26 & 44.73 & 30.61 & 29.40 \\
\hline 2006 & 25.57 & 27.57 & 29.36 & 18.05 & 24.28 & 51.65 & 20.45 & 37.97 & 39.04 & 30.44 \\
\hline 2007 & 25.54 & 29.49 & 22.89 & 19.96 & 25.43 & 53.75 & 16.55 & 37.66 & 28.08 & 28.82 \\
\hline 2008 & 22.40 & 25.60 & 18.88 & 18.36 & 17.00 & 12.67 & 19.95 & 33.50 & 25.95 & 21.59 \\
\hline 2009 & 13.53 & 14.29 & 15.21 & 12.17 & 13.16 & 14.81 & 23.99 & 16.41 & 23.30 & 16.32 \\
\hline 2010 & 14.42 & 18.36 & 13.24 & 10.91 & 12.37 & 15.38 & 27.65 & 13.32 & 14.10 & 15.53 \\
\hline 2011 & 15.53 & 35.43 & 11.93 & 12.65 & 13.35 & 17.66 & 20.06 & 5.76 & 10.97 & 15.93 \\
\hline 2012 & 12.55 & 21.11 & 6.09 & 13.86 & 14.63 & 19.17 & 21.82 & 8.44 & 11.88 & 14.39 \\
\hline 2013 & 15.50 & 20.14 & 7.97 & 14.25 & 12.57 & -49.42 & 19.19 & 9.78 & 13.26 & 7.03 \\
\hline $\begin{array}{l}\text { Average } \\
\text { per bank }\end{array}$ & 19.15 & 24.26 & 12.78 & 11.72 & 18.83 & 22.95 & 18.39 & 28.38 & 21.43 & \\
\hline
\end{tabular}

Source: These data were obtained from the McGregor BFA (2014) database.

The remaining eight banks still display a long-term trend in stability, exhibiting an average ROE of $19.4 \%$ (18.5\% for major four banks) over the period under investigation, compared to the average ROE of the four major banks (16.1\%), as reported by PwC's September 2013 report (PwC, 2013). A South African banking survey also suggests that banks are encouraging risk-weighted assets (RWA) optimisation initiatives in an attempt to restore ROE to pre-financial crisis levels. Although ROE is decreasing, so too is the cost of equity (COE), due to changing funding structures and capital requirements. This implies that the economic spread between ROE and COE is relatively the same, which suggests that ROE targets and overall expectations should be reduced in a similar manner. Investors are thus not expected to accept worse performance levels, but the risk-return relationship has merely changed to a different level than investors have become accustomed to during the pre-financial crisis period ( $\mathrm{PwC}$, 2013a).

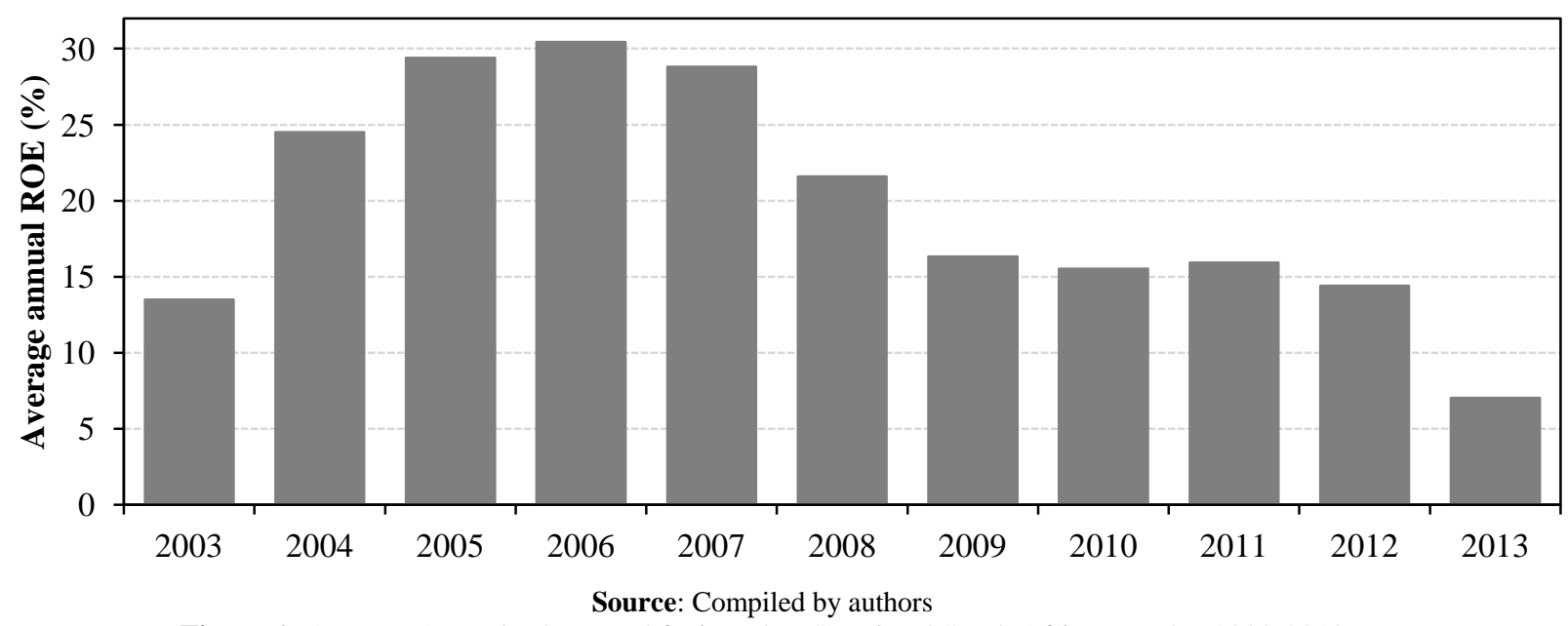

Figure 1: Average Annual ROE (\%) Of Nine The JSE-Listed South African Banks: 2003-2013

These results may be discouraging from an investor's perspective, but the South African banking industry has been a well regulated banking system compared to international standards, even before the financial crisis (The Banking Association of South Africa, 2011; 2012), thus implying financial stability and potential performance worth evaluating. This is emphasised by the gradual recovery after the financial crisis period, as the banking stability index increased, due to the gradual accumulation of liquid assets and capital. The Network Systemic Importance Index (NSII) also illustrated a slight increase in interconnectivity in the interbank market, as reported in September 2011 (SARB, 2011). The March 2013 and 2014 Financial Stability reviews, published by the South African Reserve Bank (SARB), further highlighted the South African banks' ability to improve. Although the South African banks exhibited a moderate decrease in profitability and efficiency (cost-to-income ratio) from 53.9\% in July 2012 to 
$52.2 \%$ in June 2013, it exhibited marginal increase of $0.4 \%$ in December 2013 (SARB, 2013; 2014). The net interest income ratio for the banking industry also increased from 3.4\% in December 2009 to 3.9\% in January 2014.

In addition, the 12-month cumulative net interest income exhibited an increase of $15.8 \%$ year-on-year to January 2014 (SARB, 2014). The Ernst and Young Financial Services index also highlighted the stability in the confidence of the South African financial sector during 2013. Although it remained below the long-term average of 77 index points, it remained stable between 69 and 73 index points (SARB, 2013; 2014). The standing of 72 index point during December 2013 was due to the increase in the retail banking, asset management and life insurance indices, which offset the decline in the investment banking. Furthermore, the total capital adequacy ratio improved to $15.6 \%$ in December 2013, thus further underlining the South African banking industry's stability (SARB, 2014). The liquidity in the South African banking industry was also stable during the fourth quarter of 2013, as indicated by the liquid-asset ratio and the liquid asset to short-term liabilities ratio. The liquid-asset ratio increased slightly $(0.1 \%)$ to $8.5 \%$, whereas the liquid asset to short-term liabilities ratio decreased slightly $(0.4 \%)$ to $16.7 \%$ in December 2013 (SARB, 2014).

Additional evidence (see Table 2 \& Table A in the Appendix), from an investor's perspective, also illustrates that the South African banking industry may provide more promise as a stable, profitable investment opportunity for both foreign and domestic investors, compared to some developed and emerging equity markets. This statement is justified by Table 2, which reports a summary of the arithmetic returns, geometric returns, the annualised standard deviation, and the annualised risk-adjusted returns of the nine South African banks under investigation, which is compared to the performance of several world indices over the pre-, during, and postfinancial crisis periods. These world indices comprise out of the JSE Bank index (J835), the JSE Financial index (J580), the JSE All Share index (J203), the Dow Jones, the S\&P 500, the CAC 40, the DAX, the FTSE 100 index (UKX), the Nikkei 225 index (NI225), and the Shanghai Composite index (SHCOMP).

Table 2: A Preliminary Performance Comparison Over Different Sample Periods

\begin{tabular}{lccc|cccc}
\hline \multicolumn{2}{c}{ PRE-FINANCIAL CRISIS PERIOD } & \multicolumn{3}{c}{ POST-FINANCIAL CRISIS PERIOD } \\
\hline $\begin{array}{l}\text { Arithmetic } \\
\text { Returns }\end{array}$ & $\begin{array}{c}\text { Geometric } \\
\text { Returns }\end{array}$ & $\begin{array}{c}\text { Annualised } \\
\text { Standard } \\
\text { Deviation }\end{array}$ & $\begin{array}{c}\text { Annualised } \\
\text { Risk-Adjusted } \\
\text { Returns }\end{array}$ & $\begin{array}{c}\text { Arithmetic } \\
\text { Returns }\end{array}$ & $\begin{array}{c}\text { Geometric } \\
\text { Returns }\end{array}$ & $\begin{array}{c}\text { Annualised } \\
\text { Standard } \\
\text { Deviation }\end{array}$ & $\begin{array}{c}\text { Annualised } \\
\text { Risk-Adjusted } \\
\text { Returns }\end{array}$ \\
\hline CPI & CPI & J580 & GND & CPI & CPI & J580 & S\&P 500 \\
\hline GND & GND & J203 & CPI & S\&P 500 & S\&P 500 & J203 & Dow Jones \\
\hline SFN & SFN & UKX & J580 & FSR & FSR & UKX & J580 \\
\hline ABL & ABL & S\&P 500 & SFN & Dow Jones & Dow Jones & Dow Jones & CPI \\
\hline INL & BGA & Dow Jones & J203 & DAX & DAX & S\&P 500 & J203 \\
\hline BGA & INL & CAC 40 & BGA & INL & J580 & J835 & FSR \\
\hline SBK & SBK & J835 & ABL & NED & UKX & DAX & UKX \\
\hline FSR & FSR & DAX & J835 & J580 & NED & SBK & DAX \\
\hline J835 & J835 & BGA & INL & UKX & J203 & CAC 40 & J835 \\
\hline J580 & J580 & SBK & SBK & J835 & INL & CPI & NED \\
\hline J203 & J203 & NI225 & FSR & J203 & J835 & NED & INL \\
\hline NI225 & NI225 & FSR & NI225 & CAC 40 & CAC 40 & BGA & CAC 40 \\
\hline DAX & SHCOMP & SHCOMP & DAX & GND & GND & SHCOMP & SBK \\
\hline CAC 40 & DAX & NED & SHCOMP & SFN & SBK & GND & GND \\
\hline UKX & CAC 40 & GND & CAC 40 & SBK & SFN & INL & SFN \\
\hline S\&P 500 & UKX & INL & UKX & BGA & BGA & FSR & BGA \\
\hline NED & S\&P 500 & ABL & S\&P 500 & NI225 & NI225 & SFN & NI225 \\
\hline Dow Jones & Dow Jones & SFN & Dow Jones & SHCOMP & SHCOMP & NI225 & SHCOMP \\
\hline SHCOMP & NED & CPI & NED & ABL & ABL & ABL & ABL \\
\hline & & & & & & \\
\hline
\end{tabular}


(Table 2 continued)

\begin{tabular}{|c|c|c|c|c|c|c|c|}
\hline \multicolumn{4}{|c|}{ DURING FINANCIAL CRISIS PERIOD } & \multicolumn{4}{|c|}{ ENTIRE SAMPLE PERIOD } \\
\hline $\begin{array}{l}\text { Arithmetic } \\
\text { Returns }\end{array}$ & $\begin{array}{c}\text { Geometric } \\
\text { Returns }\end{array}$ & $\begin{array}{c}\text { Annualised } \\
\text { Standard } \\
\text { Deviation } \\
\end{array}$ & $\begin{array}{c}\text { Annualised } \\
\text { Risk-Adjusted } \\
\text { Returns } \\
\end{array}$ & $\begin{array}{c}\text { Arithmetic } \\
\text { Returns }\end{array}$ & $\begin{array}{c}\text { Geometric } \\
\text { Returns }\end{array}$ & $\begin{array}{c}\text { Annualised } \\
\text { Standard } \\
\text { Deviation } \\
\end{array}$ & $\begin{array}{c}\text { Annualised } \\
\text { Risk-Adjusted } \\
\text { Returns } \\
\end{array}$ \\
\hline CPI & $\mathrm{CPI}$ & Dow Jones & CPI & $\mathrm{CPI}$ & $\mathrm{CPI}$ & J580 & CPI \\
\hline GND & GND & S\&P 500 & J203 & GND & GND & J203 & GND \\
\hline SHCOMP & $\mathrm{J} 203$ & $\mathrm{~J} 580$ & GND & SFN & SFN & Dow Jones & $\mathrm{J} 203$ \\
\hline $\mathrm{ABL}$ & SFN & UKX & SFN & FSR & FSR & S\&P 500 & J580 \\
\hline SBK & SBK & DAX & SBK & BGA & $\mathrm{J} 203$ & UKX & SFN \\
\hline SFN & DAX & $\mathrm{J} 203$ & DAX & INL & $\mathrm{J} 835$ & DAX & J835 \\
\hline BGA & $\mathrm{ABL}$ & CAC 40 & $\mathrm{ABL}$ & J835 & BGA & CAC 40 & DAX \\
\hline J203 & BGA & J835 & BGA & SBK & DAX & J835 & FSR \\
\hline J835 & J835 & SFN & J835 & $\mathrm{J} 203$ & J580 & BGA & BGA \\
\hline DAX & SHCOMP & CPI & SHCOMP & DAX & SBK & SBK & SBK \\
\hline NED & NED & BGA & NED & J580 & INL & NED & S\&P 500 \\
\hline FSR & Dow Jones & NED & FSR & S\&P 500 & S\&P 500 & FSR & Dow Jones \\
\hline Dow Jones & J580 & SBK & Dow Jones & NED & Dow Jones & SFN & INL \\
\hline J580 & S\&P 500 & FSR & J580 & Dow Jones & CAC 40 & SHCOMP & UKX \\
\hline CAC 40 & FSR & $\mathrm{ABL}$ & CAC 40 & CAC 40 & UKX & GND & CAC 40 \\
\hline S\&P 500 & CAC 40 & GND & S\&P 500 & UKX & NED & INL & NED \\
\hline UKX & UKX & SHCOMP & UKX & NI225 & NI225 & CPI & NI225 \\
\hline INL & INL & INL & INL & SHCOMP & SHCOMP & NI225 & SHCOMP \\
\hline NI225 & NI225 & NI225 & NI225 & ABL & $\mathrm{ABL}$ & ABL & $\mathrm{ABL}$ \\
\hline
\end{tabular}

Note: Each is ranked from best to worst.

Note: Barclays African Group (BGA), FirstRand Limited (FSR), Investec Limited (INL), Nedbank Group Limited (NED), the Standard Bank Group Limited (SBK), African Bank Investments Limited (ABL), Capitec Bank Holdings Limited (CPI), Grindrod Limited (GND), Sasfin Holdings Limited (SFN), the JSE Bank index (J835), the JSE Financial index (J580), the JSE All Share index (J203), the Dow Jones, the S\&P 500, the CAC 40, the DAX, the FTSE 100 index (UKX), the Nikkei 225 index (NI225), and the Shanghai Composite index (SHCOMP) are evaluated.

Source: The data were obtained from Yahoo Finance (2014) for the world indices and from the McGregor BFA (2014) database for the South African indices and shares.

From Table 2 (see also Table A in the Appendix) it is evident that CPI and GND exhibit the best performance in term of the arithmetic and geometric returns over the pre- and during financial crisis periods, and over the entire sample periods under investigation. It was also CPI and GND exhibiting the best risk-adjusted returns over the entire sample period, followed by J203 and J580, respectively. It is interesting to note that J580 exhibit the lowest annualised standard deviation over the entire sample periods and over the post-financial crisis period, where BGA exhibits the lowest annualised standard deviation of all the nine South African banks over the entire sample period. The summary from Table 2 also emphasise the results from Table 1, illustrating the poor performance of ABL, exhibiting the worst rankings over the post-financial crisis period and the entire sample period.

Overall, most of the South African banking shares performed relatively well compared to the world indices under investigation, where CPI, SFN, FSR and BGA seems to provide the most promise over the long-term. Of all the international world indices, it is the S\&P 500 and Dow Jones who exhibit a more worthly performance. Besides over the entire sample period, where DAX exhibits beter risk-adjusted returns, the S\&P 500 and Dow Jones exhibit the best risk-adjusted returns over the post-financial crisis period and the lowest annualised standard deviation during the financial crisis period. However, note that the presence of higher moments and non-normally distributed returns can influence the preliminary performance rankings reported in Table 2 (see for example Wong, Phoon \& Lean, 2008; Lamm, 2003), highliting the probability that the performance of the South African banks might have been underestimated, which motivates the need for a further evalaution. However, before such an evaluation can commenced it is important to firstly review the development of the South African banking industry, in order to enhance the understanding of the mechanisms of this industry.

\section{DEVELOPMENT OF THE SOUTH AFRICAN BANKING INDUSTRY}

After the founding of the Cape Colony in 1652, exports boomed in Port Elizabeth which led to the initiative of establishing the Standard Bank of British South Africa in 1862. In 1883 the bank was renamed to Standard Bank 
of South Africa and eventually led to the establishment of the Standard Bank Group in the late 1960s (Standard Bank, 2014). During the same time the Nederlandsche Bank voor Zuid-Afrika (NBZA) was established in the 1950s as a South African banking company and later on changed its name to the Netherlands Bank of South Africa (NBSA). In the 1970s NBSA again changed its name to Nedbank, and from the merger of Syfrets South Africa and Union Acceptances and Nedbank, led to the founding of the Nedbank Group (Nedbank, 2014). During the 1990s the South African banking industry underwent significant re-organisation and consolidation, starting when Volkskas Bank, Allied Bank, United Bank and Sage Bank merging to create the Amalgamated Banks of South Africa Limited, which is more commonly known as ABSA Group Limited (Akinboade \& Makina, 2006). In 1992, ABSA also acquired the entire shareholding of the Bankorp Group, which included Bankfin, Senbank and Trustbank (ABSA, 2013), and became Barclays African Group in 2013 after the takeover by Barclays plc. in 2005 (Fin24, 2013a). Also, the largest transaction in the history of financial services at the time occurred during 1998 and entailed the disposal of Anglo America's interest in First National Bank and Southern Life and the merger of these assets with Momentum and RMB, which led to the founding of the FirstRand Group (FNB, 2014).

Besides these distinguishable events, which led to the founding of the current four major South African banks, the promulgation of the Bank Act of 1990 led to the issuing of several banking licenses, which initiated the registration of 43 South African banks by the end of 2001 (The Banking Association of South Africa, 2012). This led to the development of a highly concentrated South African banking industry with little diversity (Hawkins, 2004), which became recognised as an immense sophisticated and reliable industry compared to international standards (Ferhani \& Sayeh, 2008). However, after the announcement of Saambou bank's financial problems in 2002, several smaller banks including BOE (the sixth largest bank at that time) suffered from a phenomenon called a 'run-on-the-bank', which led to many bankruptcies and caused a number of banks to vacillate in renewing their licenses (The Banking Association of South Africa, 2012). With the demise of many smaller banks, the South African banking industry steadily increased in concentration, with the Herfindahl-Hershman Index ranging between 0.183 to 0.190 over a period of eight years (2005-2012) and the Gini concentration index ranging between $82 \%$ and $84 \%$ from 2003 to 2013 (SARB, various years). This led to a South African banking industry that is made up of only 17 registered banks, 12 local branches of foreign banks, 41 foreign banks with approved local representative offices, and two mutual banks (The Banking Association of South Africa, 2012).

Given this amount of active banks, only five are dominating the South African banking industry, which entails FirstRand Limited, Nedbank Group Limited, Standard Bank Group Limited, Barclays African Group and Investec Limited (established in 1991). Together they control approximately $90 \%$ of total banking assets in South Africa (The Banking Association of South Africa, 2010; 2011), and approximately 84\% when excluding Investec Limited (The Banking Association of South Africa, 2012). Although the South African banking industry is smaller compared to developed countries, such as the United States (US) and the United Kingdom (UK), the performance of the South African banks can be signified by certain past achievements. For example, the South African banks achieved second place out of 144 countries in terms soundness and third place in terms of financial sector development, according to the World Economic Forum competitive Survey 2012/2013 (The Banking Association of South Africa, 2012).

This pronounced banking industry was not totally immune against the effects of the 2007-2009 global financial crisis. Some of the effects can be seen in the impact on total assets and liabilities of the South African banking industry. The total banking industry assets decreased from R3.1 trillion in December 2008 to R2.9 trillion in December 2009, whereas the total liabilities in the banking industry decreased from R2.9 trillion in December 2008 to R2.7 trillion in December 2009 (The Banking Association of South Africa, 2012). This decrease was partly due to the illiquidity of interbank markets during the financial crisis periods, where banks favoured hoarding cash instead of lending it due to higher interest spreads (Heider, Hoerova \& Holthausen, 2009). The decrease in total liabilities, on the other hand, can be partly assigned to the decrease in confidence in the South African financial sector, due to lower profit margins and uncertainty in global markets (SARB, 2010).

However, the South African banking industry illustrated a steady recovery during the post-financial crisis period, with total assets and liabilities increasing to R3.5 trillion and R3.2 trillion, respectively by June 2012 (The Banking Association of South Africa, 2012). South African banks also illustrated an improvement in the cost-toincome ratio, lowering it to $54.8 \%$ during June 2012 that was still within the international benchmark of $60 \%$ 
(SARB, 2012). Between 2010 and 2011 the South African financial sector was able to contribute approximately $10.5 \%$ of the annual Gross Domestic Product (GDP) and employed almost $4 \%$ of the total formal sector employment. The South African banking industry also possesses approximately 50\% of the total financial services sector's assets and employed almost 150000 people by 2012 (The Banking Association of South Africa, 2012). Additionally, there was also a significant increase in confidence in the South African financial service industry. The financial service index recovered from an index value below 50 and increased to an index value of 86 by December 2012 (SARB, 2013).

This moderate recovery was possible due to several factors that protected the South African financial sector against the more severe effects of global financial crisis. Some of these factors include a limited exposure to foreign assets; conservative risk management practices at domestic banks; subsidiary structure and listing requirements; and due to a sound framework for financial regulations and institutions to operate, which included the successful adoption and implementation of the Basel II Accord (National Treasury, 2011). Also, the South African economy helped to limit the exposure even further by means of a countercyclical monetary and fiscal policy; a robust monetary policy; reducing household vulnerability by the introduction of the National Credit Act to limit reckless lending; and due to a pro-active approach that is followed in terms of bank credit risk (National Treasury, 2011). The South African banking industry has also illustrated further leadership in terms of Basel compliance, where it was only one of 11 countries who issued a final draft on the Basel III regulations before the official starting date of 1 January 2013. South African banks are also considered to be well capitalised above the new Basel III requirements, although they still do not presently meet the global liquidity standards, which implies the need for some structural changes within the South African financial system (National Treasury, 2011; SARB, 2013a). Overall, the South African banking industry has illustrated superior dominance and stability by means of compliance and regulations, therefore, emphasising why investors should consider evaluating South African banking shares as possible investment options.

\section{PERFORMANCE MEASURES AND METHODOLOGY}

The efficient allocation of a portfolio is essential to obtain the required risk-return profile of an investor (Das, Kadapakkam \& Tse, 2013). The traditional approach in achieving an efficient portfolio is based on the meanvariance formulation of Markowitz (Markowitz, 1952). Based on this approach, different assets are combined which minimise the variance for a given level of return. However, some of the greatest criticisms of this approach is that it ignores the higher moments (Hentati, Kaffel \& Prigent, 2010) and that variance $\left(\sigma^{2}\right)$ does not provide a consistent perception of actual risk (Harlow, 1991). This is because $\sigma^{2}$ measures only the dispersion of returns around its historical average and penalises positive and negative deviations from the historical average in a similar manner (Lhabitant, 2004). This implies that $\sigma^{2}$ and products thereof (referring to standard deviation and beta) are unable to differentiate between downside and upside risk and thus penalise positive returns (De Wet, Krige \& Smit, 2008; Harding, 2002), which also mean that they fail to capture downside surprise (Lamm, 2003). These arguments are further emphasised by Amenc, Martellini and Sfeir (2004:2), who stated that traditional performance measures, which incorporates these risk measures as denominators, can easily be manipulated when seeking returns in "nonnormal risks", like extreme liquidity and credit risk and volatility variation risks.

\subsection{Scaled Sharpe Ratio}

From these shortfalls mentioned above, it is apparent that different portfolio allocations are possible when applying variance, standard deviation or beta as a risk measure, especially with the presence of non-normally distributed returns (see for example, Wong, Phoon \& Lean, 2008; Lamm, 2003). Nonetheless, several risk-adjusted performance measures have been developed that still apply $\sigma^{2}$ or a product thereof (referring to standard deviation and beta) as risk measures. Some of these include the Sharpe ratio (Sharpe, 1966):

$$
\text { Sharpe ratio }=\frac{r_{s}-\bar{r}_{f}}{\sigma_{s}}
$$

where $r_{s}$ is the annualised return of an asset; $\bar{r}_{f}$ is the annualised risk-free rate; and $\sigma_{s}$ is the annualised standard deviation of the asset's returns. To overcome the undesirable effects of higher moments, Gatfaoui (2012) proposes that the following adjustments can be made to the traditional Sharpe ratio to estimate an adjusted, scaled, Sharpe 
ratio:

$$
\begin{aligned}
& \text { Scaled Sharpe ratio } 1\left(S^{*}\right)=w_{-} \times \frac{e x_{-}}{\sigma_{s_{-}}}+w_{+} \times \frac{e x_{+}}{\sigma_{S_{+}}}, \\
& \text {Scaled Sharpe ratio } 2\left(S^{* *}\right)=w_{-} \times \frac{r_{s}-\bar{r}_{f}}{\sigma_{S_{-}}}+w_{+} \times \frac{r_{s}-\bar{r}_{f}}{\sigma_{s_{+}}},
\end{aligned}
$$

where $w_{-}=n_{-} \div n$; and $w_{+}=n_{+} \div n$, with $n_{-}$and $n_{+}$denoting the number of observations below and above the mean of the security's returns; $n$ is the total number of observations under investigation; $e x_{-}$denotes negative excess returns; $e x_{+}$denotes positive excess returns; $r_{s}$ denotes the annualised returns of a security; $\bar{r}_{f}$ denotes the annualised risk-free rate; and $\sigma_{s}$ denotes the annualised standard deviation of the security's returns (with $\sigma_{s_{-}}$and $\sigma_{s_{+}}$denoting the downside and upside deviations, respectively). However, the study of Reschenhofer (2004) also suggests that structural breaks can occur in higher moments, which can be misinterpreted as a deviation from normality. Several studies have proposed different procedures to detect structural breaks (see for example Chu, Stinchcombe \& White, 1996; Sowell, 1996). Although, many of these models are not always robust against heavy tails or require that the location of possible breaks are specified a prior or do not allow for dependence in the data under investigation (Reschenhofer, 2004). Also, alternative distributional stability models, such as Inoue's (2001) non-parametric test is unable to provide meaningful estimates of break locations in the presence of multiple breaks. From these findings it can be argued that it is difficult to detect multiple structural breaks accurately and to distinguish between structural breaks and other non-stationarity-like smooth transitions (see for example Reschenhofer, 1997). There is also no clear indication on how these structural breaks can be eliminated effectively, so this paper will not account for the possible presence of structural breaks in the higher moments.

Besides the limitations and modifications mentioned above, the Sharpe ratio is also based on two flawed assumptions. Firstly, the traditional Sharpe ratio assumes that the returns of the individual security are uncorrelated with the mean portfolio returns, which can lead to misleading performance rankings in the process (Sharpe, 1994). In order to overcome this problem Lo (2002) suggests that the Sharpe ratio can be adjusted for autocorrelation as follows:

$$
\eta(q) S R=\frac{q}{\sqrt{q+2 \sum_{k=1}^{q-1}(q-k) \rho_{k}}},
$$

where $S R$ is the traditional or scaled Sharpe ratio on a monthly basis, as estimated in (1); $q=12$ and $\rho_{k}$ is the $k^{t h}$ autocorrelation for returns.

The second flawed assumption is that the Sharpe ratio fails to take any benchmark/threshold of a fund into consideration to estimate the excess returns, making the evaluation of some portfolios difficult (Amenc, Martellini \& Sfeir, 2004). Also, as each investor has its own risk preference, different risk-free rates will be selected to estimate the excess returns (numerator of the Sharpe ratio), which can lead to different performance rankings. For example, the study of Copeland, Koller and Murrin (2000) and Brigham and Ehrhardt (2005) considered the 91-day Treasury Bill rate, whereas Moolman and Du Toit (2005) and De Wet (2005) considered the R157 bond yield and the R150 bond yield, respectively. Alternative studies also suggest the 10-year government bond yield (see for example Copeland, Koller \& Murrin, 2000), whereas Botha (2007) and Favre-Bulle and Pache (2003) recommended the 3month JIBAR rate and the 3-month LIBOR rate, respectively.

In addition, to overcome the flaws posed by the traditional risk measures, several studies have recommended modified versions of the traditional Sharpe ratio. These modified versions include the modified Sharpe ratio (Gregoriou \& Gueyie, 2003); the modified Value at Risk (MVaR) model (Favre \& Galeano, 2002); the Conditional Drawdown at Risk (CDaR) model; the Conditional Value at Risk (CVaR) model (Krokhmal, Palmquist \& Uryasev, 2002); the Cornish-fisher ratio (Liang \& Park, 2007); as well as the Polynomial Goal Programming process (PGP) (Davies, Kat \& Lu, 2009). However, the popular Value at Risk-based measures are still flawed by their sensitivity to the underlying parameters and the reliance on normally distributed risk factors (Van Dyk, Van Vuuren \& Heymans, 2014). Also, as the presence of normality is infrequent, especially when evaluating emerging market returns (Hwang \& Pedersen, 2004), the divergence from normality occurring in the higher moments of the return distributions will limit the Sharpe ratio's performance ranking abilities (Amin \& Kat, 2003; Kat, 2003). 


\subsection{Omega Ratio}

In order to overcome several of the limitations posed by the Sharpe ratio, this paper will also consult the Omega ratio (Keating \& Shadwick, 2002), which treats upside and downside risk differently, thus "heeding" the criticism of the mean-variance portfolio optimisation of Markowitz (Gilli, Schumann, Di Tollo \& Cabej, 2011:95). The Omega ratio also includes all the information that are encoded in the moments (namely, variance, mean, skewness, \& kurtosis) (Togher \& Barsbay, 2007); it does not require any assumptions about any moments (De Wet, Krige \& Smit, 2008); and thus no assumptions are required on the utility function of an investor (Favre-Bulle \& Pache, 2003). The Omega ratio is, therefore, beneficial as it considers both the upside potential (higher partial moments) and downside potential (lower partial moments) of an investment over the entire distribution (Kazemi, Schneeweis \& Gupta, 2003), whereas popular ratios like the Sortino ratio (see Sortino \& Price, 1994) and the Calmar ratio (see Young, 1991) consider only the lower partial moments (downside risk \& maximum drawdown, respectively). Overall, the Omega ratio considers the possibility for returns to be not normally distributed, which enables it to serve as an appropriate benchmark to the Sharpe ratio. The Omega ratio can, therefore, be illustrated as follows (Keating \& Shadwick, 2002):

$$
\Omega(r)=\frac{\int_{r}^{b}(1-F(x)) d x}{\int_{a}^{r} F(x) d x}
$$

where $r$ denotes the selected threshold; $x$ denotes the random one-period return of an investment; $a$ and $b$ denote the upper and lower bounds of the return distribution, respectively; $\left[\int_{r}^{b}(1-F(x)) d x\right]$ denotes the upside potential; and $\left[\int_{a}^{r} F(x) d x\right]$ denotes the downside potential.

However, the Omega ratio, like all traditional performance ratios, is still fallible in the sense that it is backward-looking (Togher \& Barsbay, 2007). To overcome this shortcoming, and the uncertainty regarding the future performance of South African banks after the downgrade, this paper will also consult the Kalman filter (Kalman, 1960). The Kalman filter will provide an out-of-sample forecast, which will enable the estimation of 'future' Share and Omega ratios to determine if the South African banking industry can still be expected to be a feasible investment option after the downgrade.

\subsection{Kalman Filter}

The Kalman filter (Kalman, 1960) is a Bayesian updating scheme that maximises the likelihood of correctly estimating unknown parameter values (Koch, 2006). The filter addresses the general problem of attempting to estimate the state $\left[x \in \Re^{n}\right]$ of a discrete, time-controlled process governed by the linear stochastic difference equation (Faff, Hillier \& Hillier, 2000):

$$
x_{t}=F x_{t-1}+B u_{t-1}+w_{t-1},
$$

with a measurement $\left[z \in \mathfrak{R}^{n}\right]$ :

$$
z_{t}=H x_{t}+v_{t}
$$

The random variables $w$ and $v$ represent process white noise and measurement white noise, respectively. These are assumed to be independent of each other (i.e. 0 correlation between them) with normal probability distributions (Faff, Hillier \& Hillier, 2000):

$$
\begin{aligned}
& w(\cdot) \sim N(0, Q), \\
& v(\cdot) \sim N(0, R) .
\end{aligned}
$$


In practice, the process noise covariance $Q$ and measurement noise covariance $R$ matrices (here variance matrices, since $\rho=0$ ) might change with each time step, however, here they are assumed to be constant (Koch, 2006). These values were obtained by maximum likelihood methods.

The $2 \times 1$ (in this case) state transition matrix $F$ links the state at the previous time step $t-1$ to the current state at step $t$, assuming no driving function or process noise. The $2 \times 2$ control matrix $B$ relates the optional control input $u \in \Re^{l}$ to the state $x$. The $2 \times 1$ matrix $H$ in the measurement relates the state to the measurement $z_{k}$. In practice, $F$ and $H$ might change with each time step, but here they are both assumed to be constant. The mechanical process to be followed is (Koch, 2006):

\section{PREDICT}

Project state 1 time step ahead

Project error covariance 1 step ahead

$$
\begin{aligned}
& \hat{x}_{t \mid t-1}=F_{t} \hat{x}_{t-1 \mid t-1}+B_{t} u_{t}, \\
& P_{t \mid t-1}=F_{t} P_{t-1 \mid t-1} F_{t}^{T}+Q_{t},
\end{aligned}
$$

\section{UPDATE}

\section{Compute Kalman gain}

Update estimate with measurement $y_{t}$

Update error covariance

$$
\begin{aligned}
& K_{t}=P_{t \mid t-1} H_{t}^{T}\left(H_{t} P_{t \mid t-1} H_{t}^{T}+R_{t}\right)^{-1}, \\
& \hat{x}_{t \mid t}=\hat{x}_{t \mid t-1}+K_{t}\left(y_{t}-H_{t} \hat{x}_{t \mid t-1}\right), \\
& P_{t \mid t}=\left(I-K_{t} H_{t}\right) P_{t \mid t-1}
\end{aligned}
$$

where $\hat{x}$ is the estimated state; $F$ is the state transition matrix (i.e., transition between states); $u$ represents the control variables; $B$ is the control matrix (i.e., mapping control to state variables); $P$ is the state variance matrix (i.e., error of estimation); $Q$ is the process variance matrix (i.e., error due to process); $y$ represents the measurement variables; $H$ is the measurement matrix (i.e., mapping measurements onto the state); $K$ is the Kalman gain; and $R$ is the measurement variance matrix (i.e., error from measurements). The subscript $t \mid t$ represents the current time period; $t-1 \mid t-1$ represents the previous time period; and $t \mid t-1$ represents the intermediate steps.

The process discussed above will be used to generate 6-, 12-, and 24-month in-sample and out-of-sample forecasts, respectively. The out-of-sample forecasts will be used to estimate 'future' Omega and Sharpe ratios, which will determine the expected risk-adjusted performance of the South African banks. However, before this can be accomplished must the creditability of the Kalman filter's forecasting ability first be determined, through the evaluation of the in-sample forecasts. The Mean Absolute Error $(M A E)$; the Mean Squared Error (MSE), the Mean Absolute Percentage Error (MAPE), and the Root Mean Squared Error (RMSE) will be consulted to establish the accuracy of these forecasts, which can be formulated as follow (QMS, 2009; Makridakis, Wheelwright \& Hyndman, 1998):

$$
\begin{gathered}
M A E=\frac{\sum_{t=1}^{n}\left|Y_{t}-F_{t}\right|}{n}, \\
M S E=\frac{\sum_{t=1}^{n}\left(Y_{t}-F_{t}\right)^{2}}{n}, \\
M A P E=\frac{\sum_{t=1}^{n}\left|P E_{t}\right|}{n}, \\
\text { RMSE }=\sqrt{\frac{\sum\left(Y_{t}-F_{t}\right)^{2}}{n},}
\end{gathered}
$$


where $Y_{t}$ are the actual returns at time $t ; F_{t}$ are the forecast returns at time $t ; n$ is the number of observations and $P E_{t}=\left(\frac{Y_{t}-F_{t}}{Y_{t}}\right) \times 100$.

\subsection{Data}

Daily closing share prices of the nine South African banks, obtained from the McGregor BFA (2014) database, were used. To benchmark the performance of these banks, the same indices will be included in the performance analysis as reported in Table 2. The daily closing index values of the South African indices were obtained from the McGregor BFA (2014) database, whereas the data of the other world indices were obtained from Yahoo Finance (2014), respectively. Daily 3-month JIBAR yields, used as an appropriate risk-free proxy (see Botha, 2007) to estimate the excess returns for the Sharpe ratio, were obtained from the McGregor BFA (2014) database. The average 3-month JIBAR yield will also be applied as the threshold for the Omega ratio.

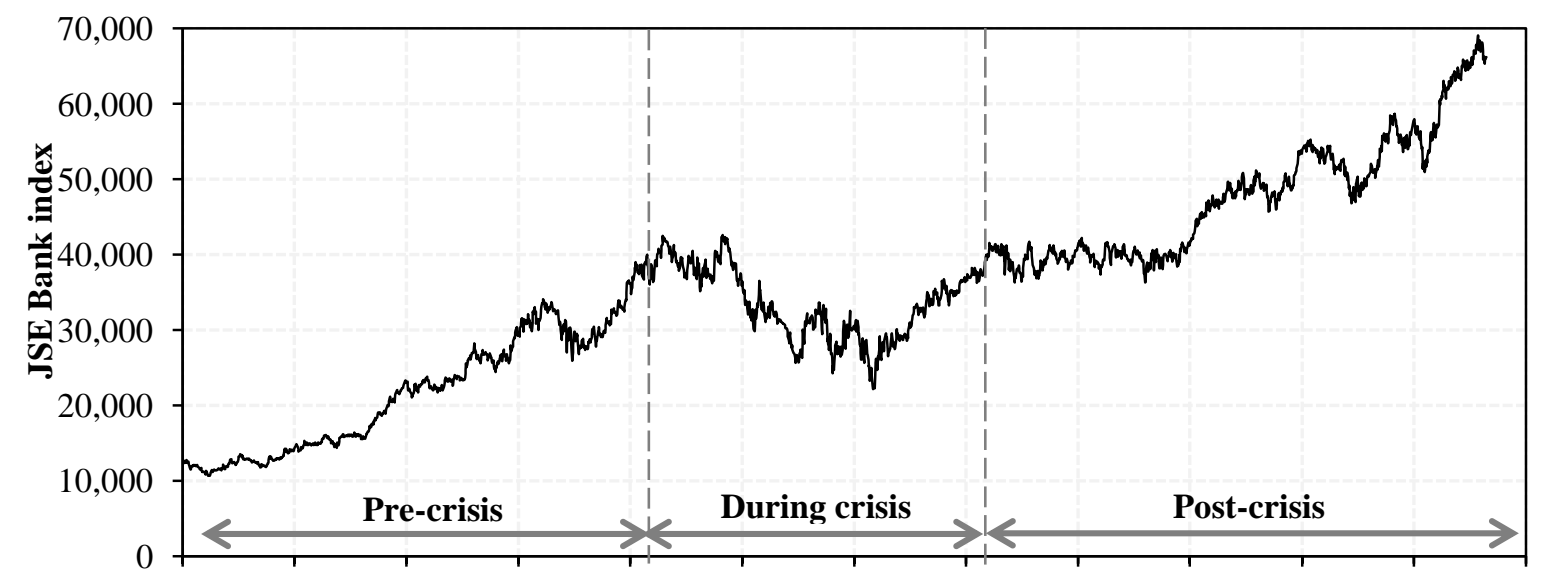

Jan-03 Jan-04 Jan-05 Jan-06 Jan-07 Jan-08 Jan-09 Jan-10 Jan-11 Jan-12 Jan-13 Jan-14 Jan-15

Source: The data were obtained from the McGregor BFA (2014) database.

Figure 2: Sample Periods Under Investigation - Illustrated By The JSE Bank Index

The risk-adjusted performance evaluation will be conducted over three time periods (see Figure 2) that will include a pre-financial crisis period (January 2003 to December 2006), a during financial crisis period (January 2007 to December 2009) and a post-financial crisis period (January 2010 to August 2014). The 'during crisis' period was constructed to incorporate key events of the 2007-2009 financial crisis to ensure that the effect of the crisis can be evaluated effectively. This period starts by incorporating the date when the Federal Home Loan Mortgage Corporation (Freddie Mac) announced that no more risky subprime mortgages and mortgage-related securities will be bought (27 February 2007). It also includes the event when Northern Rock was taken into state ownership by the Treasury of the United Kingdom (17 February 2008); the announcements of Lehman Brothers Holdings Incorporated filing for bankruptcy on 15 September 2008); and continues until after the announcement that Obama signed the American Recovery and Reinvestment Act of 2009, which included a variety of tax cuts and spending measures that were intended to promote economic recovery in the US.

\section{RESULTS}

The two higher moments (skewness \& kurtosis) of the investments proxies under investigation were first investigated. The presence/absence of normality/non-normality was also ascertained, as the divergence from normality occurring in the higher moments of the return distributions limits the traditional Sharpe ratio's performance ranking abilities. This was determined by consulting several normality tests, based on the empirical distribution function (EDF), moments and correlation, respectively, to generate more conclusive results. The normality tests that are based on the EDF include the Kolmogorov-Smirnov (KS) tests with the Lilliefors correction, the Cramér-von Misses' (CVM) test and the Anderson-Darling (AD) test. Normality tests that are based on moments and correlation will entail the Jarque-Bera (JB) test and the Shapiro-Wilk (SW) test, respectively. These analyses 
will be conducted with the EViews 7 program (QMS, 2009) and the IBM $^{\circledR}$ SPPS Statistics, version 22 program (IBM, 2013), respectively.

The presence of higher moments and non-normality is overwhelming during all three time periods under investigation, including the entire sample period (see Table 3). All time series are leptokurtic (fat-tailed: kurtosis $>3$ ), which reinforces results found by Fung and Hsieh (1999). Some individual returns series exhibit negative skewness, implying the possibility of downside surprises (see for example Lamm, 2003), where a relatively low skewness is overall present with most of the other returns. On average, a positive skewness is present during both the pre- and during financial crisis periods, although a negative average skewness is present during the post-financial crisis period and the entire sample period under investigation. These inconsistencies in terms of skewness and the presence of a high kurtosis will make it difficult to provide an accurate performance comparison between the different periods under investigation, as the higher moments will cause the standard deviation to give a misinterpretation of the overall risk. This argument is further accentuated by the results found on the presence of non-normality. All the normality tests reject the presence of normality for all the return series under investigation, which is not uncommon in equity markets (see for example Hwang \& Pedersen, 2004). The only exception is for J835 during the post-financial crises period, where the $K S$ test did not reject the null hypothesis for normality. Overall, these findings suggest that the traditional Sharpe ratio will generate inaccurate performance rankings (see for example Bernardo \& Ledoit, 2000; Lamm, 2003), which must be prevented by adopting the scaled Sharpe ratios, based on Gatfaoui's (2012) methodology, and the Omega ratio as an additional benchmark. 
Table 3: Higher Moments And Presence Of Non-Normality Over Different Sample Periods

\begin{tabular}{|c|c|c|c|c|c|c|c|c|c|c|c|c|c|c|}
\hline & \multicolumn{7}{|c|}{ PRE-FINANCIAL CRISIS PERIOD } & \multicolumn{7}{|c|}{ DURING-FINANCIAL CRISIS PERIOD } \\
\hline & Skew & Kurt & JB & CVM & AD & $\mathbf{K S}$ & SW & Skew & Kurt & JB & CVM & AD & $\mathbf{K S}$ & SW \\
\hline ABL & -0.05 & 5.17 & 196 & 0.93 & 5.05 & 0.05 & 0.98 & 0.15 & 3.91 & 29 & 0.25 & 1.66 & 0.04 & 0.99 \\
\hline BGA & 0.31 & 5.98 & 387 & 1.01 & 5.42 & 0.05 & 0.97 & 0.27 & 4.37 & 68 & 0.55 & 3.04 & 0.05 & 0.99 \\
\hline CPI & 0.54 & 8.71 & $>1000$ & 5.17 & 26.19 & 0.12 & 0.91 & 0.09 & 6.56 & 396 & 3.43 & 16.61 & 0.12 & 0.93 \\
\hline FSR & 0.04 & 4.63 & 111 & 0.35 & 2.03 & 0.04 & 0.99 & 0.03 & 4.06 & 35 & 0.24 & 1.41 & 0.04 & 0.99 \\
\hline GND & 0.89 & 7.99 & $>1000$ & 6.86 & 33.77 & 0.14 & 0.90 & 0.07 & 6.44 & 371 & 0.95 & 5.66 & 0.06 & 0.96 \\
\hline INL & -0.04 & 4.73 & 125 & 0.95 & 4.85 & 0.05 & 0.98 & 0.32 & 5.45 & 201 & 0.81 & 4.97 & 0.06 & 0.97 \\
\hline NED & -0.08 & 4.58 & 105 & 1.03 & 5.80 & 0.06 & 0.98 & 0.26 & 5.10 & 146 & 0.58 & 3.59 & 0.06 & 0.98 \\
\hline SBK & 0.15 & 4.46 & 92 & 0.44 & 2.61 & 0.04 & 0.99 & 0.32 & 4.68 & 101 & 0.78 & 4.22 & 0.07 & 0.98 \\
\hline SFN & 1.50 & 19.21 & $>1000$ & 16.15 & 76.17 & 0.22 & 0.77 & 0.05 & 8.01 & 784 & 8.18 & 38.06 & 0.18 & 0.87 \\
\hline $\mathrm{J} 203$ & -0.18 & 5.74 & 319 & 0.36 & 2.66 & 0.04 & 0.98 & 0.02 & 4.95 & 119 & 0.61 & 3.81 & 0.05 & 0.98 \\
\hline J835 & 0.13 & 5.46 & 256 & 0.60 & 3.50 & 0.05 & 0.98 & 0.19 & 4.20 & 49 & 0.57 & 3.27 & 0.06 & 0.99 \\
\hline J580 & -0.10 & 6.90 & 634 & 0.66 & 4.35 & 0.05 & 0.97 & 0.21 & 4.44 & 71 & 0.51 & 3.24 & 0.05 & 0.98 \\
\hline Dow Jones & 0.18 & 4.28 & 73 & 0.33 & 2.22 & 0.04 & 0.99 & 0.22 & 6.64 & 421 & 0.95 & 6.23 & 0.07 & 0.95 \\
\hline CAC 40 & 0.29 & 5.20 & 216 & 0.96 & 5.77 & 0.05 & 0.98 & -0.03 & 8.73 & $>1000$ & 1.54 & 9.38 & 0.07 & 0.93 \\
\hline DAX & 0.11 & 4.77 & 132 & 0.94 & 5.32 & 0.05 & 0.98 & 0.05 & 8.25 & 862 & 1.16 & 7.48 & 0.07 & 0.94 \\
\hline S\&P 500 & 0.15 & 4.40 & 86 & 0.39 & 2.63 & 0.04 & 0.99 & 0.01 & 6.33 & 348 & 1.15 & 7.55 & 0.08 & 0.95 \\
\hline UKX & 0.38 & 6.12 & 429 & 0.91 & 5.87 & 0.05 & 0.97 & 0.00 & 6.73 & 435 & 1.16 & 7.04 & 0.07 & 0.96 \\
\hline NI225 & -0.31 & 5.12 & 202 & 0.59 & 3.69 & 0.04 & 0.98 & -0.35 & 6.88 & 485 & 1.51 & 8.90 & 0.08 & 0.95 \\
\hline SHCOMP & 0.08 & 4.86 & 146 & 0.49 & 3.06 & 0.04 & 0.98 & -0.23 & 3.81 & 27 & 0.62 & 3.26 & 0.07 & 0.99 \\
\hline 3-month JIBAR & 1.62 & 4.28 & 505 & 20.1 & 113.36 & 0.28 & 0.71 & -0.29 & 1.81 & 55 & 2.24 & 17.67 & 0.12 & 0.92 \\
\hline
\end{tabular}


(Table 3 continued)

\begin{tabular}{|c|c|c|c|c|c|c|c|c|c|c|c|c|c|c|}
\hline & \multicolumn{7}{|c|}{ POST-FINANCIAL CRISIS PERIOD } & \multicolumn{7}{|c|}{ ENTIRE SAMPLE PERIOD } \\
\hline & Skew & Kurt & JB & CVM & AD & KS & SW & Skew & Kurt & JB & CVM & AD & KS & SW \\
\hline ABL & -11.25 & 202.26 & $>1000$ & 19.03 & 107.59 & 0.19 & 0.45 & -9.40 & 217.58 & $>1000$ & 17.62 & 105.34 & 0.12 & 0.64 \\
\hline BGA & -0.05 & 5.11 & 216 & 0.65 & 3.83 & 0.05 & 0.98 & 0.22 & 5.83 & 998 & 3.28 & 18.93 & 0.06 & 0.97 \\
\hline CPI & 0.21 & 6.40 & 569 & 2.16 & 12.00 & 0.07 & 0.96 & 0.48 & 10.17 & $>1000$ & 14.45 & 74.56 & 0.10 & 0.90 \\
\hline FSR & -0.29 & 5.00 & 211 & 0.22 & 1.26 & 0.03 & 0.99 & -0.06 & 5.23 & 604 & 1.51 & 8.91 & 0.04 & 0.98 \\
\hline GND & 0.12 & 5.43 & 290 & 2.02 & 10.70 & 0.07 & 0.97 & 0.32 & 8.40 & $>1000$ & 10.34 & 53.75 & 0.09 & 0.93 \\
\hline INL & -0.03 & 4.18 & 68 & 0.44 & 2.58 & 0.03 & 0.99 & 0.16 & 6.60 & $>1000$ & 3.54 & 20.66 & 0.05 & 0.96 \\
\hline NED & 0.06 & 4.08 & 57 & 0.17 & 1.20 & 0.03 & 0.99 & 0.12 & 5.76 & 936 & 2.37 & 14.46 & 0.05 & 0.97 \\
\hline SBK & -0.07 & 4.11 & 61 & 0.20 & 1.58 & 0.03 & 0.99 & 0.23 & 5.69 & 901 & 2.61 & 15.79 & 0.05 & 0.97 \\
\hline SFN & 0.72 & 8.51 & $>1000$ & 14.69 & 66.66 & 0.21 & 0.86 & 0.81 & 13.70 & $>1000$ & 39.41 & 182.52 & 0.20 & 0.83 \\
\hline $\mathrm{J} 203$ & -0.15 & 4.47 & 109 & 0.61 & 3.96 & 0.05 & 0.98 & -0.08 & 6.68 & $>1000$ & 3.35 & 21.19 & 0.05 & 0.96 \\
\hline $\mathrm{J835}$ & -0.02 & 4.15 & 64 & 0.21 & 1.52 & $0.02 *$ & 0.99 & 0.13 & 5.62 & 844 & 2.58 & 15.91 & 0.05 & 0.97 \\
\hline J580 & -0.14 & 4.93 & 185 & 0.61 & 3.93 & 0.05 & 0.98 & 0.05 & 6.44 & $>1000$ & 3.69 & 22.84 & 0.06 & 0.96 \\
\hline Dow Jones & 0.05 & 5.10 & 214 & 0.40 & 2.67 & 0.03 & 0.98 & 0.15 & 5.54 & 796 & 1.67 & 11.06 & 0.04 & 0.98 \\
\hline CAC 40 & 0.01 & 5.17 & 228 & 0.55 & 3.84 & 0.04 & 0.98 & 0.06 & 7.13 & $>1000$ & 3.03 & 18.83 & 0.05 & 0.96 \\
\hline DAX & -0.15 & 4.51 & 114 & 0.74 & 4.60 & 0.04 & 0.98 & 0.02 & 6.34 & $>1000$ & 2.95 & 17.53 & 0.05 & 0.97 \\
\hline S\&P 500 & -0.02 & 5.64 & 339 & 0.44 & 2.95 & 0.04 & 0.98 & 0.04 & 5.67 & 865 & 1.92 & 12.77 & 0.05 & 0.97 \\
\hline UKX & 0.01 & 4.39 & 94 & 0.29 & 1.86 & 0.03 & 0.99 & 0.09 & 7.03 & $>1000$ & 2.89 & 18.64 & 0.05 & 0.96 \\
\hline NI225 & -0.43 & 4.83 & 198 & 0.71 & 3.91 & 0.05 & 0.98 & -0.45 & 8.71 & $>1000$ & 4.86 & 28.95 & 0.07 & 0.94 \\
\hline SHCOMP & -0.14 & 4.14 & 66 & 0.65 & 3.73 & 0.04 & 0.99 & -0.15 & 5.39 & 704 & 3.19 & 18.66 & 0.05 & 0.97 \\
\hline 3-month JIBAR & 1.10 & 3.62 & 252 & 9.32 & 55.09 & 0.24 & 0.86 & 0.84 & 2.69 & 355 & 15.41 & 97.39 & 0.13 & 0.90 \\
\hline
\end{tabular}

Note: * does not reject the null hypothesis of normality. The rest of the normality tests reject the null hypothesis at a 5\% level of statistical significance. Also, "Skew" denotes skewness and "Kurt" denotes kurtosis.

Note: Barclays African Group (BGA), FirstRand Limited (FSR), Investec Limited (INL), Nedbank Group Limited (NED), the Standard Bank Group Limited (SBK), African Bank Investments Limited (ABL), Capitec Bank Holdings Limited (CPI), Grindrod Limited (GND), Sasfin Holdings Limited (SFN), the JSE Bank index (J835), the JSE Financial index (J580), the JSE All Share index (J203), the Dow Jones, the S\&P 500, the CAC 40, the DAX, the FTSE 100 index (UKX), the Nikkei 225 index (NI225), and the Shanghai Composite index (SHCOMP) are evaluated.

Source: The data were obtained from Yahoo Finance (2014) for the world indices and from the McGregor BFA (2014) database for the South African indices and shares.

A risk-adjusted performance comparison of the different investment proxies over the different sample periods under investigation is provided next. These rankings will be accumulated from the traditional Sharpe ratio (see Equation 1), an autocorrelation adjusted (SC) Sharpe ratio (see Equation 4), two scaled versions of the Sharpe ratio (see Equation 2 for $S^{*}$ and Equation 3 for $S^{* *}$ ), which are also adjusted for autocorrelation, and from the Omega ratio (see Equation 5). The first observation worth reporting from Table 4 and 5 is that there is no relationship between the rankings of the different risk-adjusted performance measures. These rankings accentuate the impact that correlation and higher moments have and provide a motivation for why future studies must always adjust for these occurrences. Another important observation is the respectable overall performance of South African banks over the different periods under investigation. 
Table 4: Risk-Adjusted Performance Rankings Over Pre- And During Financial Crisis Period

\begin{tabular}{|c|c|c|c|c|c|c|c|c|c|c|c|c|}
\hline \multicolumn{13}{|c|}{ PRE-FINANCIAL CRISIS PERIOD } \\
\hline \multicolumn{2}{|c|}{ Traditional Sharpe } & \multicolumn{2}{|c|}{ SC Sharpe } & \multicolumn{2}{|c|}{ Sharpe $\mathbf{S}^{*}$} & \multicolumn{2}{|c|}{ SC Sharpe $\mathbf{S}^{*}$} & \multicolumn{2}{|c|}{ Sharpe $\mathbf{S * *}$} & \multicolumn{2}{|c|}{ SC Sharpe $\mathbf{S * *}$} & \multirow{2}{*}{$\begin{array}{c}\text { Omega } \\
\text { Rank }\end{array}$} \\
\hline Rank & Est. & Rank & Est. & Rank & Est. & Rank & Est. & Rank & Est. & Rank & Est. & \\
\hline GND & 2.35 & $\mathrm{CPI}$ & 5.90 & SFN & -0.03 & GND & -0.08 & GND & 3.78 & CPI & 8.72 & SHCOMP \\
\hline CPI & 1.88 & SFN & 4.49 & CPI & -0.04 & BGA & -0.09 & CPI & 2.78 & SFN & 6.93 & ABL \\
\hline SFN & 1.53 & GND & 3.24 & GND & -0.05 & SFN & -0.09 & SFN & 2.36 & GND & 5.22 & CPI \\
\hline J580 & 1.36 & INL & 3.23 & ABL & -0.06 & J580 & -0.09 & BGA & 2.07 & INL & 4.84 & NI225 \\
\hline BGA & 1.33 & $\mathrm{~J} 203$ & 3.23 & INL & -0.06 & $\mathrm{~J} 203$ & -0.09 & J580 & 2.02 & $\mathrm{~J} 203$ & 4.79 & BGA \\
\hline $\mathrm{ABL}$ & 1.26 & $\mathrm{ABL}$ & 2.57 & NED & -0.06 & J835 & -0.09 & $\mathrm{ABL}$ & 1.88 & $\mathrm{ABL}$ & 3.84 & SBK \\
\hline $\mathrm{J} 203$ & 1.24 & J580 & 2.34 & BGA & -0.06 & DAX & -0.10 & $\mathrm{~J} 203$ & 1.84 & BGA & 3.52 & FSR \\
\hline $\mathrm{J} 835$ & 1.06 & BGA & 2.26 & J580 & -0.07 & CAC 40 & -0.10 & J835 & 1.64 & J580 & 3.46 & J835 \\
\hline INL & 1.03 & J835 & 1.82 & FSR & -0.07 & UKX & -0.10 & INL & 1.55 & J835 & 2.82 & J580 \\
\hline SBK & 0.96 & SBK & 1.70 & NI225 & -0.07 & NED & -0.11 & SBK & 1.54 & SBK & 2.72 & DAX \\
\hline FSR & 0.89 & FSR & 1.59 & DAX & -0.07 & CPI & -0.11 & FSR & 1.38 & FSR & 2.48 & CAC 40 \\
\hline NI225 & 0.62 & NI225 & 1.32 & J835 & -0.07 & SBK & -0.12 & DAX & 0.90 & NI225 & 1.86 & S\&P 500 \\
\hline DAX & 0.60 & DAX & 1.06 & $\mathrm{~J} 203$ & -0.07 & $\mathrm{ABL}$ & -0.12 & SHCOMP & 0.89 & DAX & 1.60 & Dow Jones \\
\hline SHCOMP & 0.57 & SHCOMP & 1.01 & UKX & -0.07 & NI225 & -0.12 & NI225 & 0.88 & SHCOMP & 1.58 & GND \\
\hline CAC 40 & 0.45 & UKX & 0.80 & CAC 40 & -0.07 & FSR & -0.13 & CAC 40 & 0.71 & UKX & 1.27 & INL \\
\hline UKX & 0.28 & CAC 40 & 0.80 & SHCOMP & -0.07 & Dow Jones & -0.16 & UKX & 0.44 & CAC 40 & 1.25 & $\mathrm{~J} 203$ \\
\hline S\&P 500 & 0.06 & S\&P 500 & 0.17 & SBK & -0.07 & INL & -0.18 & S\&P 500 & 0.09 & S\&P 500 & 0.27 & UKX \\
\hline Dow Jones & -0.03 & Dow Jones & -0.10 & S\&P 500 & -0.08 & SHCOMP & -0.20 & NED & -0.05 & Dow Jones & -0.16 & NED \\
\hline NED & -0.03 & NED & -0.11 & Dow Jones & -0.08 & S\&P 500 & -0.24 & Dow Jones & -0.05 & NED & -0.16 & SFN \\
\hline
\end{tabular}


(Table 4 continued)

\begin{tabular}{|c|c|c|c|c|c|c|c|c|c|c|c|c|}
\hline \multicolumn{13}{|c|}{ DURING FINANCIAL CRISIS PERIOD } \\
\hline \multicolumn{2}{|c|}{ Traditional Sharpe } & \multicolumn{2}{|c|}{ SC Sharpe } & \multicolumn{2}{|c|}{ Sharpe S* } & \multicolumn{2}{|c|}{ SC Sharpe $\mathbf{S}^{*}$} & \multicolumn{2}{|c|}{ Sharpe $\mathbf{S} * *$} & \multicolumn{2}{|c|}{ SC Sharpe $\mathbf{S}^{* *}$} & \multirow{2}{*}{$\begin{array}{c}\text { Omega } \\
\text { Rank }\end{array}$} \\
\hline Rank & Est. & Rank & Est. & Rank & Est. & Rank & Est. & Rank & Est. & Rank & Est. & \\
\hline CPI & 0.59 & CPI & 1.54 & FSR & 0.07 & FSR & 0.19 & CPI & 0.82 & CPI & 2.16 & GND \\
\hline GND & -0.05 & GND & -0.08 & $\mathrm{~J} 580$ & 0.07 & $\mathrm{~J} 580$ & 0.18 & GND & -0.07 & GND & -0.12 & SFN \\
\hline SBK & -0.10 & SBK & -0.14 & INL & 0.06 & INL & 0.17 & SFN & -0.14 & SBK & -0.23 & DAX \\
\hline SFN & -0.10 & $\mathrm{ABL}$ & -0.17 & NI225 & 0.06 & S\&P 500 & 0.16 & SBK & -0.16 & $\mathrm{ABL}$ & -0.27 & SHCOMP \\
\hline J203 & -0.11 & $\mathrm{~J} 203$ & -0.18 & S\&P 500 & 0.06 & CAC 40 & 0.16 & $\mathrm{~J} 203$ & -0.16 & J203 & -0.27 & Dow Jones \\
\hline ABL & -0.12 & BGA & -0.20 & UKX & 0.06 & NED & 0.15 & $\mathrm{ABL}$ & -0.19 & BGA & -0.31 & $\mathrm{~J} 203$ \\
\hline SHCOMP & -0.13 & SHCOMP & -0.26 & Dow Jones & 0.06 & UKX & 0.12 & SHCOMP & -0.20 & SHCOMP & -0.40 & CAC 40 \\
\hline BGA & -0.14 & SFN & -0.31 & CAC 40 & 0.06 & NI225 & 0.11 & BGA & -0.22 & SFN & -0.41 & S\&P 500 \\
\hline J835 & -0.17 & NED & -0.31 & NED & 0.05 & Dow Jones & 0.09 & $\mathrm{~J} 835$ & -0.26 & NED & -0.45 & $\mathrm{ABL}$ \\
\hline DAX & -0.18 & DAX & -0.35 & SHCOMP & -0.01 & SHCOMP & 0.00 & DAX & -0.26 & DAX & -0.48 & CPI \\
\hline NED & -0.22 & J835 & -0.55 & J835 & -0.02 & J835 & -0.05 & NED & -0.32 & $\mathrm{~J} 835$ & -0.85 & UKX \\
\hline FSR & -0.30 & FSR & -0.62 & BGA & -0.03 & SFN & -0.05 & FSR & -0.45 & FSR & -0.94 & BGA \\
\hline $\mathrm{J} 580$ & -0.43 & NI225 & -0.91 & SFN & -0.03 & BGA & -0.07 & J580 & -0.62 & NI225 & -1.42 & SBK \\
\hline CAC 40 & -0.44 & S\&P 500 & -1.32 & $\mathrm{ABL}$ & -0.04 & DAX & -0.09 & INL & -0.62 & J580 & -1.90 & $\mathrm{~J} 835$ \\
\hline Dow Jones & -0.44 & J580 & -1.32 & DAX & -0.04 & CPI & -0.10 & CAC 40 & -0.62 & S\&P 500 & -1.91 & J580 \\
\hline INL & -0.45 & UKX & -1.40 & CPI & -0.05 & $\overline{A B L}$ & -0.11 & Dow Jones & -0.63 & UKX & -2.00 & FSR \\
\hline S\&P 500 & -0.50 & INL & -1.49 & SBK & -0.05 & GND & -0.11 & S\&P 500 & -0.72 & INL & -2.05 & NI225 \\
\hline NI225 & -0.53 & Dow Jones & -1.71 & GND & -0.06 & SBK & -0.15 & UKX & -0.77 & Dow Jones & -2.41 & INL \\
\hline UKX & -0.54 & CAC 40 & -1.73 & J203 & -0.07 & J203 & -0.15 & NI225 & -0.83 & CAC 40 & -2.42 & NED \\
\hline
\end{tabular}

Note: Each ranking is from best to worst and "Est." denotes the estimate; Omega ranking entails a combination of the downside and upside ranking.

Note: Barclays African Group (BGA), FirstRand Limited (FSR), Investec Limited (INL), Nedbank Group Limited (NED), the Standard Bank Group Limited (SBK), African Bank Investments Limited (ABL), Capitec Bank Holdings Limited (CPI), Grindrod Limited (GND), Sasfin Holdings Limited (SFN), the JSE Bank index (J835), the JSE Financial index (J580), the JSE All Share index (J203), the Dow Jones, the S\&P 500, the CAC 40, the DAX, the FTSE 100 index (UKX), the Nikkei 225 index (NI225), and the Shanghai Composite index (SHCOMP) are evaluated.

Source: The data were obtained from Yahoo Finance (2014) for the world indices and from the McGregor BFA (2014) database for the South African indices and shares. 
Table 5: Risk-Adjusted Performance Rankings Over Post-Financial Crisis Period And Entire Sample Period

\begin{tabular}{|c|c|c|c|c|c|c|c|c|c|c|c|c|}
\hline \multicolumn{13}{|c|}{ POST-FINANCIAL CRISIS PERIOD } \\
\hline \multicolumn{2}{|c|}{ Traditional Sharpe } & \multicolumn{2}{|c|}{ SC Sharpe } & \multicolumn{2}{|c|}{ Sharpe $\mathbf{S *}$} & \multicolumn{2}{|c|}{ SC Sharpe S* } & \multicolumn{2}{|c|}{ Sharpe S** } & \multicolumn{2}{|c|}{ SC Sharpe $\mathbf{S}^{* *}$} & \multirow{2}{*}{$\begin{array}{l}\text { Omega } \\
\text { Rank }\end{array}$} \\
\hline Rank & Est. & Rank & Est. & Rank & Est. & Rank & Est. & Rank & Est. & Rank & Est. & \\
\hline S\&P 500 & 0.96 & S\&P 500 & 1.57 & SHCOMP & 0.07 & SHCOMP & 0.18 & S\&P 500 & 1.47 & S\&P 500 & 2.39 & CPI \\
\hline Dow Jones & 0.88 & Dow Jones & 1.43 & $\mathrm{ABL}$ & 0.06 & $\mathrm{ABL}$ & 0.14 & Dow Jones & 1.38 & Dow Jones & 2.24 & J580 \\
\hline CPI & 0.83 & CPI & 1.37 & SFN & -0.04 & SFN & -0.07 & CPI & 1.21 & UKX & 2.06 & $\mathrm{~J} 835$ \\
\hline J580 & 0.78 & INL & 1.33 & NI225 & -0.06 & NI225 & -0.07 & J580 & 1.15 & INL & 2.02 & $\mathrm{ABL}$ \\
\hline J203 & 0.65 & UKX & 1.31 & CPI & -0.06 & CPI & -0.08 & FSR & 0.96 & $\mathrm{CPI}$ & 1.99 & INL \\
\hline FSR & 0.64 & J580 & 1.14 & GND & -0.06 & GND & -0.11 & J203 & 0.95 & J580 & 1.67 & SBK \\
\hline DAX & 0.60 & FSR & 0.95 & BGA & -0.07 & NED & -0.11 & UKX & 0.90 & FSR & 1.41 & FSR \\
\hline UKX & 0.57 & J203 & 0.93 & DAX & -0.07 & CAC 40 & -0.15 & DAX & 0.88 & J203 & 1.34 & NED \\
\hline J835 & 0.46 & DAX & 0.86 & J203 & -0.07 & DAX & -0.16 & J835 & 0.71 & DAX & 1.26 & BGA \\
\hline NED & 0.42 & J835 & 0.68 & CAC 40 & -0.07 & S\&P 500 & -0.16 & NED & 0.68 & J835 & 1.06 & \begin{tabular}{|l|}
$\mathrm{J} 203$ \\
\end{tabular} \\
\hline INL & 0.38 & NED & 0.65 & S\&P 500 & -0.07 & J203 & -0.16 & INL & 0.58 & NED & 1.03 & Dow Jones \\
\hline CAC 40 & 0.21 & CAC 40 & 0.56 & J580 & -0.07 & J580 & -0.17 & CAC 40 & 0.31 & CAC 40 & 0.85 & S\&P 500 \\
\hline GND & 0.14 & SFN & 0.25 & FSR & -0.07 & Dow Jones & -0.17 & GND & 0.20 & SFN & 0.38 & SFN \\
\hline SBK & 0.12 & GND & 0.19 & Dow Jones & -0.07 & UKX & -0.18 & SBK & 0.19 & SBK & 0.29 & UKX \\
\hline SFN & 0.09 & SBK & 0.19 & SBK & -0.07 & BGA & -0.18 & SFN & 0.13 & GND & 0.28 & NI225 \\
\hline BGA & 0.07 & BGA & 0.11 & INL & -0.08 & INL & -0.19 & BGA & 0.11 & BGA & 0.17 & DAX \\
\hline NI225 & -0.04 & NI225 & -0.05 & UKX & -0.08 & J835 & -0.20 & NI225 & -0.05 & NI225 & -0.07 & GND \\
\hline SHCOMP & -0.81 & $\mathrm{ABL}$ & -1.38 & $\mathrm{~J} 835$ & -0.08 & SBK & -0.21 & SHCOMP & -1.29 & SHCOMP & -3.47 & SHCOMP \\
\hline $\mathrm{ABL}$ & -1.01 & SHCOMP & -2.18 & NED & -0.08 & FSR & -0.22 & $\mathrm{ABL}$ & -2.56 & $\mathrm{ABL}$ & -3.49 & CAC 40 \\
\hline
\end{tabular}


(Table 5 continued)

\begin{tabular}{|c|c|c|c|c|c|c|c|c|c|c|c|c|}
\hline \multicolumn{13}{|c|}{ ENTIRE SAMPLE PERIOD } \\
\hline \multicolumn{2}{|c|}{ Traditional Sharpe } & \multicolumn{2}{|c|}{ SC Sharpe } & \multicolumn{2}{|c|}{ Sharpe $\mathbf{S}^{*}$} & \multicolumn{2}{|c|}{ SC Sharpe $\mathbf{S}^{*}$} & \multicolumn{2}{|c|}{ Sharpe $\mathbf{S} * *$} & \multicolumn{2}{|c|}{ SC Sharpe $\mathbf{S}^{* *}$} & \multirow{2}{*}{$\begin{array}{c}\text { Omega } \\
\text { Rank }\end{array}$} \\
\hline Rank & Est. & Rank & Est. & Rank & Est. & Rank & Est. & Rank & Est. & Rank & Est. & \\
\hline CPI & 1.10 & CPI & 2.78 & ABL & 0.07 & ABL & 0.18 & CPI & 1.57 & CPI & 3.94 & SHCOMP \\
\hline GND & 0.66 & J580 & 1.53 & SHCOMP & 0.01 & SHCOMP & 0.02 & GND & 0.95 & $\mathrm{~J} 580$ & 2.19 & ABL \\
\hline J203 & 0.51 & GND & 1.11 & SFN & -0.04 & NI225 & -0.06 & $\mathrm{~J} 203$ & 0.72 & GND & 1.60 & CPI \\
\hline SFN & 0.48 & J203 & 0.87 & NI225 & -0.04 & SFN & -0.09 & SFN & 0.70 & SFN & 1.23 & NI225 \\
\hline J580 & 0.44 & SFN & 0.85 & CPI & -0.05 & Dow Jones & -0.11 & J580 & 0.64 & J203 & 1.22 & BGA \\
\hline J835 & 0.39 & DAX & 0.65 & GND & -0.05 & INL & -0.11 & J835 & 0.58 & DAX & 0.93 & SBK \\
\hline DAX & 0.36 & FSR & 0.62 & INL & -0.07 & GND & -0.11 & FSR & 0.52 & FSR & 0.92 & FSR \\
\hline FSR & 0.35 & S\&P 500 & 0.61 & $\mathrm{~J} 203$ & -0.07 & CPI & -0.11 & DAX & 0.51 & S\&P 500 & 0.91 & J835 \\
\hline BGA & 0.34 & J835 & 0.54 & BGA & -0.07 & DAX & -0.12 & BGA & 0.51 & J835 & 0.82 & J580 \\
\hline SBK & 0.29 & BGA & 0.47 & CAC 40 & -0.07 & UKX & -0.13 & SBK & 0.44 & BGA & 0.72 & DAX \\
\hline INL & 0.23 & Dow Jones & 0.46 & J580 & -0.07 & J203 & -0.14 & INL & 0.33 & Dow Jones & 0.70 & CAC 40 \\
\hline S\&P 500 & 0.18 & SBK & 0.41 & DAX & -0.07 & J580 & -0.14 & S\&P 500 & 0.27 & SBK & 0.64 & S\&P 500 \\
\hline Dow Jones & 0.14 & INL & 0.32 & NED & -0.07 & S\&P 500 & -0.15 & Dow Jones & 0.22 & INL & 0.47 & Dow Jones \\
\hline UKX & 0.08 & UKX & 0.15 & UKX & -0.07 & CAC 40 & -0.16 & UKX & 0.12 & UKX & 0.22 & GND \\
\hline CAC 40 & 0.07 & CAC 40 & 0.13 & FSR & -0.07 & BGA & -0.16 & CAC 40 & 0.11 & CAC 40 & 0.19 & INL \\
\hline NED & 0.04 & NED & 0.05 & $\mathrm{~J} 835$ & -0.07 & NED & -0.17 & NED & 0.06 & NED & 0.08 & $\mathrm{~J} 203$ \\
\hline SHCOMP & -0.16 & SHCOMP & -0.28 & S\&P 500 & -0.07 & FSR & -0.17 & SHCOMP & -0.24 & SHCOMP & -0.42 & NED \\
\hline $\mathrm{ABL}$ & -0.53 & $\mathrm{ABL}$ & -0.77 & Dow Jones & -0.07 & SBK & -0.18 & ABL & -1.02 & $\mathrm{ABL}$ & -1.50 & SFN \\
\hline
\end{tabular}

Note: Each ranking is from best to worst and "Est." denotes the estimate; Omega ranking entails a combination of the downside and upside ranking.

Note: Barclays African Group (BGA), FirstRand Limited (FSR), Investec Limited (INL), Nedbank Group Limited (NED), the Standard Bank Group Limited (SBK), African Bank Investments Limited (ABL), Capitec Bank Holdings Limited (CPI), Grindrod Limited (GND), Sasfin Holdings Limited (SFN), the JSE Bank index (J835), the JSE Financial index (J580), the JSE All Share index (J203), the Dow Jones, the S\&P 500, the CAC 40, the DAX, the FTSE 100 index (UKX), the Nikkei 225 index (NI225), and the Shanghai Composite index (SHCOMP) are evaluated.

Source: The data were obtained from Yahoo Finance (2014) for the world indices and from the McGregor BFA (2014) database for the South African indices and shares.

Overall, South African banks performed relatively well against the other world indices. During the pre- and during financial crisis periods CPI, SFN, and GND exhibit the more dominant performance, as ranked by the different Sharpe versions. These three banks ranked under the top five investments, although the SC adjusted scaled Sharpe ratio $\left(S^{*}\right)$ reports different rankings. During the pre-financial crisis period GND, BGA, and SFN ranked as the top three performers, whereas FSR, J580, and INL are ranked as the top three performers during the financial crisis period. 
However, the Omega rankings for the pre- and during crisis period exhibit an odd deviation, as SHCOMP, $\mathrm{ABL}$, and CPI ranked as the top three performers during the pre-financial crisis period and GND, SFN, and DAX during the financial crisis period (see Table $4 \& 5$ ). The Omega ratio also ranks CPI, J580, and J835 as the top three performers during post-financial crisis. Although, according to the different Sharpe versions the S\&P 500 and Dow Jones exhibit more dominate performance. Furthermore, the rankings provided by the SC adjusted scaled Sharpe ratio $\left(S^{*}\right)$ for the post-financial crisis period and for the entire sample period are questionable. The Omega rankings for the entire sample period is also doubtful, as SHCOMP and ABL are ranked as top performers. The rankings of $\mathrm{ABL}$ can be assigned to possible breaks in the higher moments, as the ABL debt crisis led to a substantial decrease in share price, which may not be accurately reflected in these performance measures. Is it, however, only the SC adjusted scaled Sharpe ratio $\left(S^{* *}\right)$ which reported more convincing rankings during the post-financial crisis period and the entire sample period, and which accentuate the results reported in Table 1 and 2. With the SC adjusted scaled Sharpe ratio $\left(S^{* *}\right)$, S\&P 500, Dow Jones, UKX, INL, and CPI are ranked as the top performers during the post-financial crisis period, whereas CPI, J580, GND, SFN, and J203 are ranked as the top performers during the entire sample period under investigation (see Table $4 \& 5$ ).

Overall, South African banks illustrated respectable performance compared to world indices during the different time periods under investigation, with ABL as the exception. Especially, CPI, GND, and SFN exhibit the most promising results, which are followed by S\&P 500, Dow Jones, SHCOMP, and DAX as the more competitive world indices. Nonetheless, from these results it can be argued that South African banks can be considered as competitive investments options. Though, these rankings are still based on historical returns and with the downgrade of some of the South African banks will create uncertainty, making investors more hesitate to invest in these banking shares. In order to determine if these shares can still be expected to be relatively competitive, the Kalman filter will be applied to generate future returns (6-, 12-, and 24-month forecasts, respectively), from which 'future' Sharpe and Omega ratios will be estimated. However, before future performance rankings can be estimated it is important to firstly establish the reliability of the Kalman filter's ability to forecast. This will be accomplished by evaluating the 6-, 12-, and 24-month in-sample forecasts with the Mean Absolute Error (MAE); the Mean Squared Error (MSE), the Mean Absolute Percentage Error (MAPE), and the Root Mean Squared Error (RMSE), respectively.

Table 6: The Accuracy Of The 6-Month, 12-Month And 24-Month In-Sample Forecasts

\begin{tabular}{|c|c|c|c|c|c|c|c|c|c|c|c|c|}
\hline & \multicolumn{4}{|c|}{$\begin{array}{l}\text { 6-month forecast } \\
\text { (July } 2013 \text { to December 2013) }\end{array}$} & \multicolumn{4}{|c|}{$\begin{array}{l}\text { 12-month forecast } \\
\text { (September } 2013 \text { to August 2014) }\end{array}$} & \multicolumn{4}{|c|}{$\begin{array}{l}\text { 24-month forecast } \\
\text { (September } 2012 \text { to August 2014) }\end{array}$} \\
\hline & MAE & MSE & MAPE & RMSE & MAE & MSE & MAPE & RMSE & MAE & MSE & MAPE & RMSE \\
\hline$\overline{\mathrm{ABL}}$ & 0.02 & 0.00 & 1.09 & 0.04 & 0.09 & 0.29 & 2.27 & 0.54 & 0.04 & 0.03 & 1.65 & 0.16 \\
\hline BGA & 0.01 & 0.00 & 1.29 & 0.02 & 0.01 & 0.00 & 1.71 & 0.01 & 0.01 & 0.00 & 1.54 & 0.01 \\
\hline CPI & 0.01 & 0.00 & 1.49 & 0.01 & 0.01 & 0.00 & 1.66 & 0.01 & 0.01 & 0.00 & 1.81 & 0.02 \\
\hline FSR & 0.01 & 0.00 & 1.24 & 0.02 & 0.01 & 0.00 & 4.00 & 0.01 & 0.01 & 0.00 & 1.63 & 0.01 \\
\hline GND & 0.01 & 0.00 & 2.09 & 0.01 & 0.01 & 0.00 & 2.50 & 0.02 & 0.01 & 0.00 & 1.21 & 0.02 \\
\hline INL & 0.01 & 0.00 & 1.09 & 0.02 & 0.01 & 0.00 & 4.03 & 0.01 & 0.01 & 0.00 & 1.35 & 0.02 \\
\hline NED & 0.01 & 0.00 & 1.30 & 0.01 & 0.01 & 0.00 & 1.77 & 0.01 & 0.01 & 0.00 & 2.30 & 0.01 \\
\hline SBK & 0.01 & 0.00 & 1.58 & 0.01 & 0.01 & 0.00 & 1.85 & 0.01 & 0.01 & 0.00 & 1.38 & 0.01 \\
\hline SFN & 0.01 & 0.00 & 1.22 & 0.02 & 0.01 & 0.00 & $>10$ & 0.02 & 0.01 & 0.00 & 2.94 & 0.02 \\
\hline $\mathbf{J 2 0 3}$ & 0.01 & 0.00 & 1.30 & 0.01 & 0.01 & 0.00 & 2.70 & 0.01 & 0.01 & 0.00 & 2.62 & 0.01 \\
\hline J835 & 0.01 & 0.00 & 1.41 & 0.01 & 0.01 & 0.00 & 1.57 & 0.01 & 0.01 & 0.00 & 1.47 & 0.01 \\
\hline J580 & 0.01 & 0.00 & 1.17 & 0.01 & 0.01 & 0.00 & 2.10 & 0.01 & 0.01 & 0.00 & 3.63 & 0.01 \\
\hline CAC 40 & 0.01 & 0.00 & 1.78 & 0.01 & 0.01 & 0.00 & 5.93 & 0.01 & 0.01 & 0.00 & 1.99 & 0.01 \\
\hline DAX & 0.01 & 0.00 & 1.21 & 0.01 & 0.01 & 0.00 & 2.41 & 0.01 & 0.01 & 0.00 & 1.89 & 0.01 \\
\hline Dow Jones & 0.01 & 0.00 & 1.46 & 0.01 & 0.01 & 0.00 & 2.23 & 0.01 & 0.01 & 0.00 & 2.42 & 0.01 \\
\hline S\&P 500 & 0.01 & 0.00 & 1.53 & 0.01 & 0.01 & 0.00 & 1.89 & 0.01 & 0.01 & 0.00 & $>10$ & 0.01 \\
\hline UKX & 0.01 & 0.00 & 4.22 & 0.01 & 0.01 & 0.00 & 1.65 & 0.01 & 0.01 & 0.00 & 2.16 & 0.01 \\
\hline NI225 & 0.02 & 0.00 & 1.77 & 0.04 & 0.01 & 0.00 & 3.54 & 0.02 & 0.04 & 0.07 & 1.63 & 0.27 \\
\hline SHCOMP & 0.18 & 0.22 & 0.48 & 0.47 & 0.03 & 0.00 & 0.91 & 0.05 & 0.03 & 0.02 & 1.47 & 0.14 \\
\hline 3-Month JIBAR & 0.00 & 0.00 & 0.75 & 0.00 & 0.00 & 0.00 & 0.14 & 0.00 & 0.00 & 0.00 & 0.16 & 0.00 \\
\hline
\end{tabular}

Note: Barclays African Group (BGA), FirstRand Limited (FSR), Investec Limited (INL), Nedbank Group Limited (NED), the Standard Bank Group Limited (SBK), African Bank Investments Limited (ABL), Capitec Bank Holdings Limited (CPI), Grindrod Limited (GND), Sasfin Holdings Limited (SFN), the JSE Bank index (J835), the JSE Financial index (J580), the JSE All Share index (J203), the Dow Jones, the S\&P 500, the CAC 40, the DAX, the FTSE 100 index (UKX), the Nikkei 225 index (NI225), and the Shanghai Composite index (SHCOMP) are evaluated.

Source: Compiled by authors. 


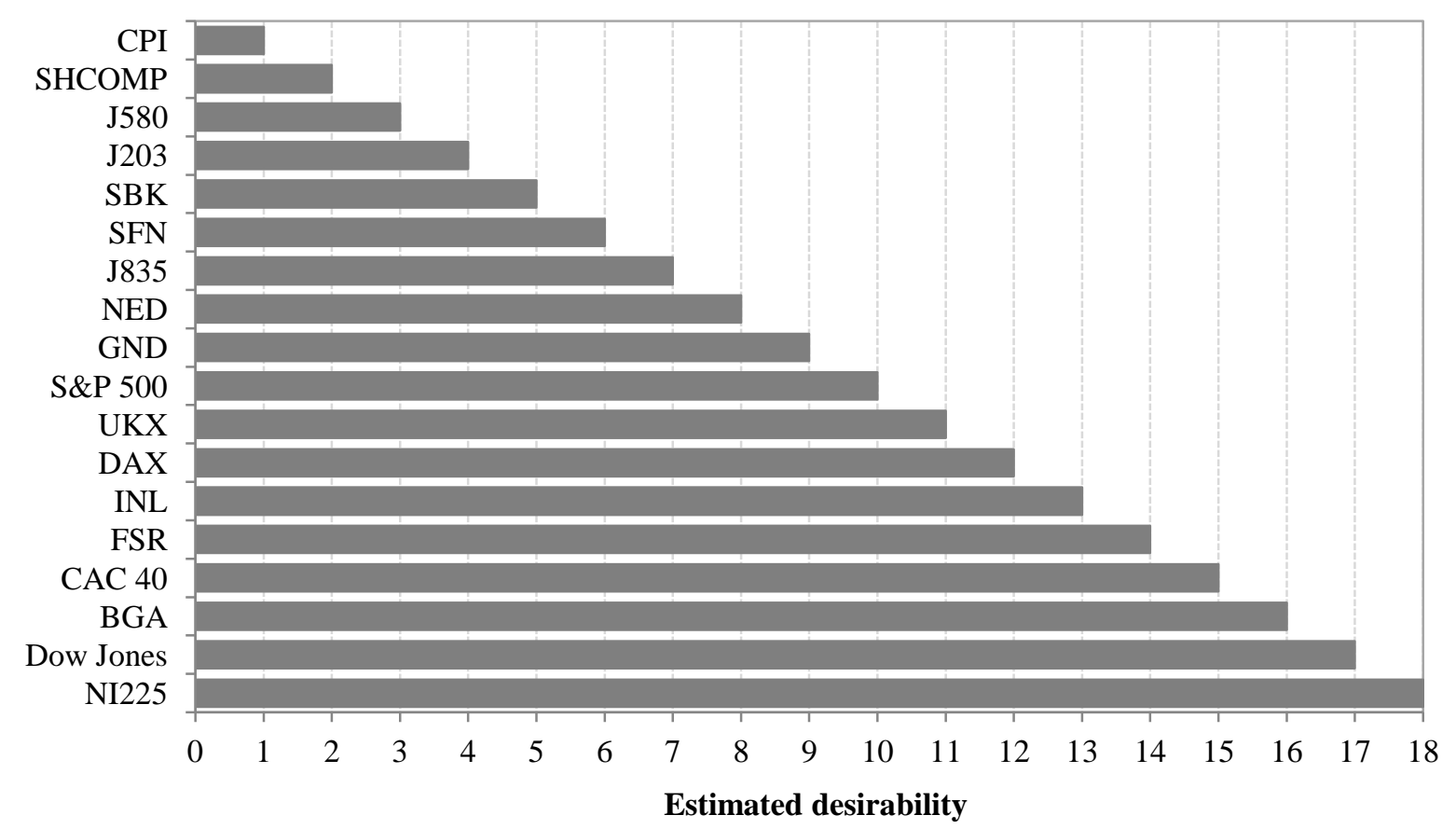

Note: The estimated desirability is based on a combined evaluation of the SC adjusted Sharpe ratio and the Omega ratio. 18 represents the most desirable investment and 1 the least desirable.

Note: Barclays African Group (BGA), FirstRand Limited (FSR), Investec Limited (INL), Nedbank Group Limited (NED), the Standard Bank Group Limited (SBK), African Bank Investments Limited (ABL), Capitec Bank Holdings Limited (CPI), Grindrod Limited (GND), Sasfin Holdings Limited (SFN), the JSE Bank index (J835), the JSE Financial index (J580), the JSE All Share index (J203), the Dow Jones, the S\&P 500, the CAC 40, the DAX, the FTSE 100 index (UKX), the Nikkei 225 index (NI225), and the Shanghai Composite index (SHCOMP) are evaluated.

Source: Compiled by author.

Figure 3: Risk-Adjusted Performance Rankings Based On The 6-Month Out-Of-Sample Forecast

From the results reported in Table 6 it can be argued that due to the relative small in-sample forecast errors, the Kalman filter can be considered as a reliable forecasting tool, which also supports the findings of Brooks, Faff and McKenzie (1998). Although the forecast error increases as the forecast range increases, (see for example Ozcan, 2009), the Kalman filter's forecast ability is still deemed suitable for this paper. The next step of the empirical study is to generate 6-, 12-, and 24-month out-of-sample forecasts, which are used to establish the possible future riskadjusted performance of the South African banks. Since ABL has provided no returns since August 2014, it is excluded from further evaluations. Also, the forecast returns exhibited no downside risk for some of the shares and indices under investigation, making it impossible to estimate the scaled Sharpe ratios. There were also no deviations found between the rankings based on the traditional Sharpe ratio and the SC adjusted Sharpe ratio, hence this paper evaluates only the rankings generated from the Omega ratio and the SC adjusted Sharpe ratio. 


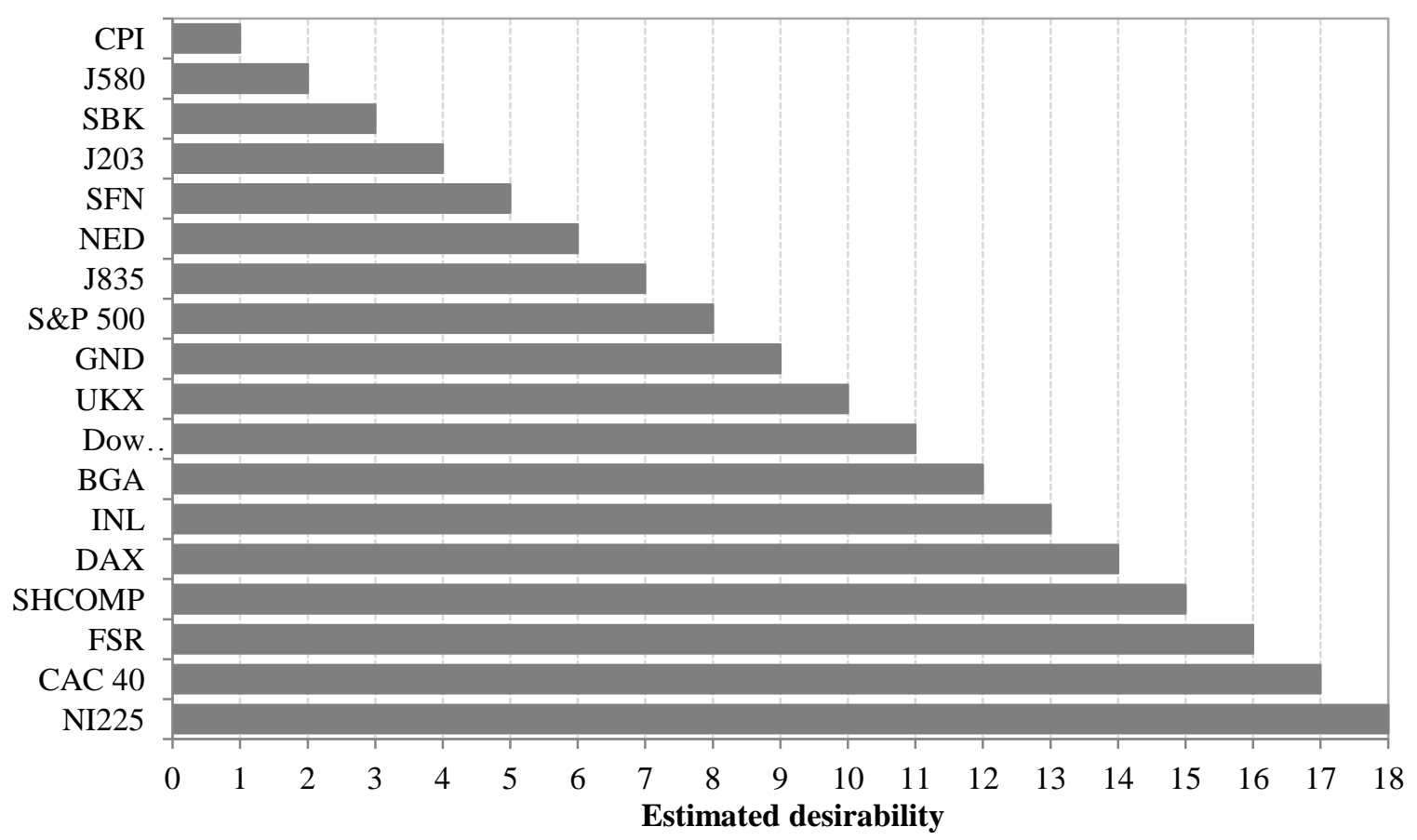

Note: The estimated desirability is based on a combined evaluation of the SC adjusted Sharpe ratio and the Omega ratio. 18 represents the most desirable investment and 1 the least desirable.

Note: Barclays African Group (BGA), FirstRand Limited (FSR), Investec Limited (INL), Nedbank Group Limited (NED), the Standard Bank Group Limited (SBK), African Bank Investments Limited (ABL), Capitec Bank Holdings Limited (CPI), Grindrod Limited (GND), Sasfin Holdings Limited (SFN), the JSE Bank index (J835), the JSE Financial index (J580), the JSE All Share index (J203), the Dow Jones, the S\&P 500, the CAC 40, the DAX, the FTSE 100 index (UKX), the Nikkei 225 index (NI225), and the Shanghai Composite index (SHCOMP) are evaluated.

Source: Compiled by author.

Figure 4: Risk-Adjusted Performance Rankings Based On The 12-Month Out-Of-Sample Forecast

From the rankings reported in Table B to D in the Appendix, it is clear that the downgrade of the four major South African banks and of CPI is expected to have a significant effect on their future risk-adjusted performance (see also Figure 3, 4 \& 5). Based on the SC adjusted Sharpe ratio and the Omega ratio, CPI is expected to perform the worst of all the shares and indices under investigation (see Table B to D in the Appendix). Also, the 6-month and 12-month performance evaluation suggest that NED will perform the third worst of the four major banks, followed by SBK (see Figure $3 \& 4$ ). Although, the 24-month performance evaluation suggests that NED will improve, outperforming BGA (see Figure 5) that is considered to be the best performing South African bank over the 6-month performance evaluation.

The 12-month performance evaluation also suggests that FSR will be the best performing bank of the four major banks, but will be outperformed by NI225 and CAC 40, respectively. However, the 24-month performance evaluation suggests that FSR will improve and will outperform all the shares and indices under investigation, followed by NI225, J835, INL and SFN, respectively. It is also interesting to note that dominant world indices, such as the Dow Jones, CAC 40, and S\&P 500 are expected to decrease in performance, based on the 6-month and 24month performance evaluation. Also, from all the world indices, the 6-month and 24-month performance evaluations suggest that SHCOMP to be the worst performing index, followed by J580 and J203, respectively. Although the South African banks are not overall the top performers, the forecast performance evaluations suggest that most of the South African shares will be able to outperform J580 and J203, respectively. Furthermore, even if the 6-month and 12-month performance evaluation suggest that J835 lost investment confidence, the 24-month performance evaluation suggests a long-term improvement, outperforming all the shares and indices, except FSR and NI225 (see Figure 5). 


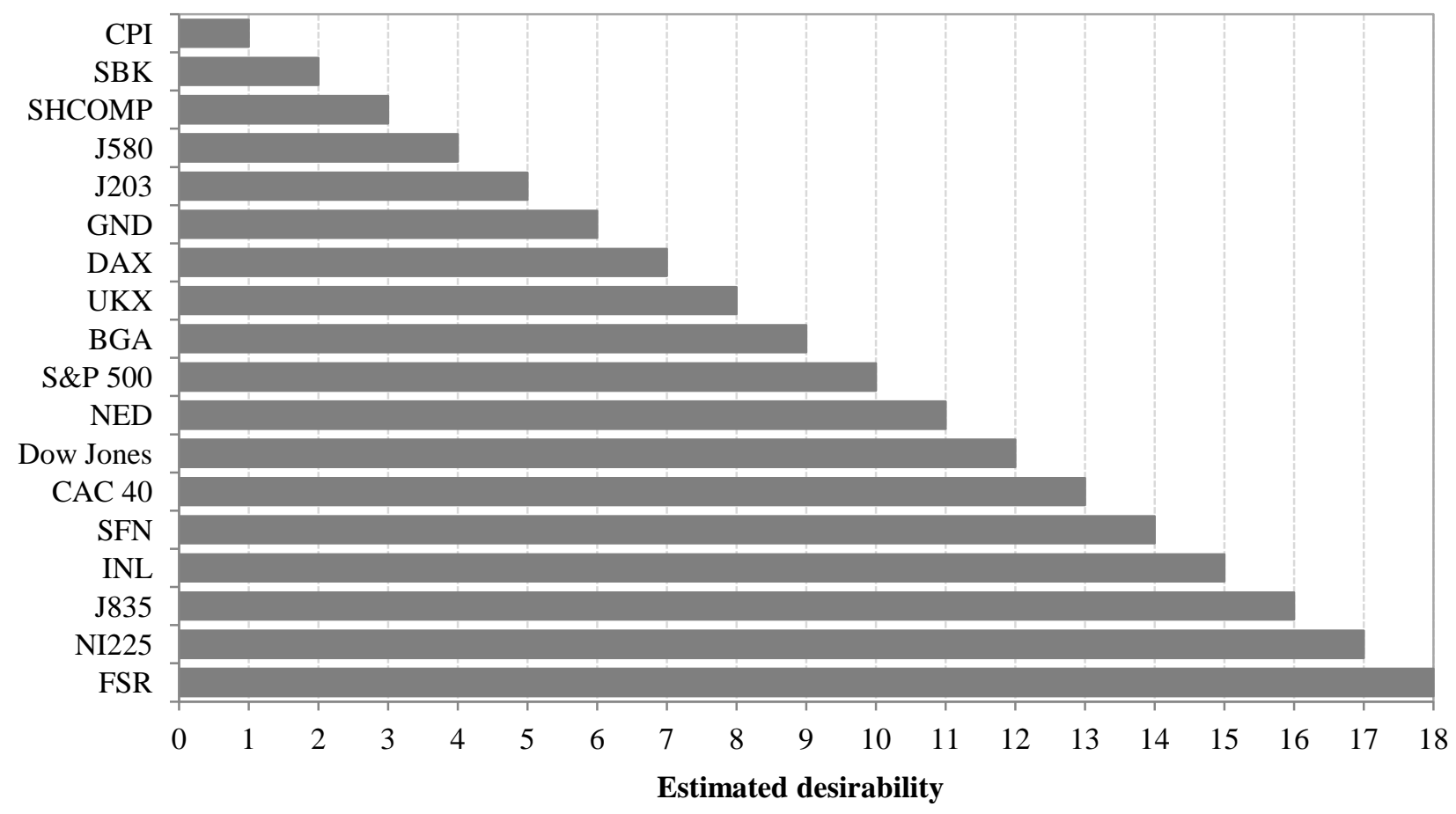

Note: The estimated desirability is based on a combined evaluation of the SC adjusted Sharpe ratio and the Omega ratio. 18 represents the most desirable investment and 1 the least desirable.

Note: Barclays African Group (BGA), FirstRand Limited (FSR), Investec Limited (INL), Nedbank Group Limited (NED), the Standard Bank Group Limited (SBK), African Bank Investments Limited (ABL), Capitec Bank Holdings Limited (CPI), Grindrod Limited (GND), Sasfin Holdings Limited (SFN), the JSE Bank index (J835), the JSE Financial index (J580), the JSE All Share index (J203), the Dow Jones, the S\&P 500, the CAC 40, the DAX, the FTSE 100 index (UKX), the Nikkei 225 index (NI225), and the Shanghai Composite index (SHCOMP) are evaluated.

Source: Compiled by author.

Figure 5: Risk-Adjusted Performance Rankings Based On The 24-Month Out-Of-Sample Forecast. 


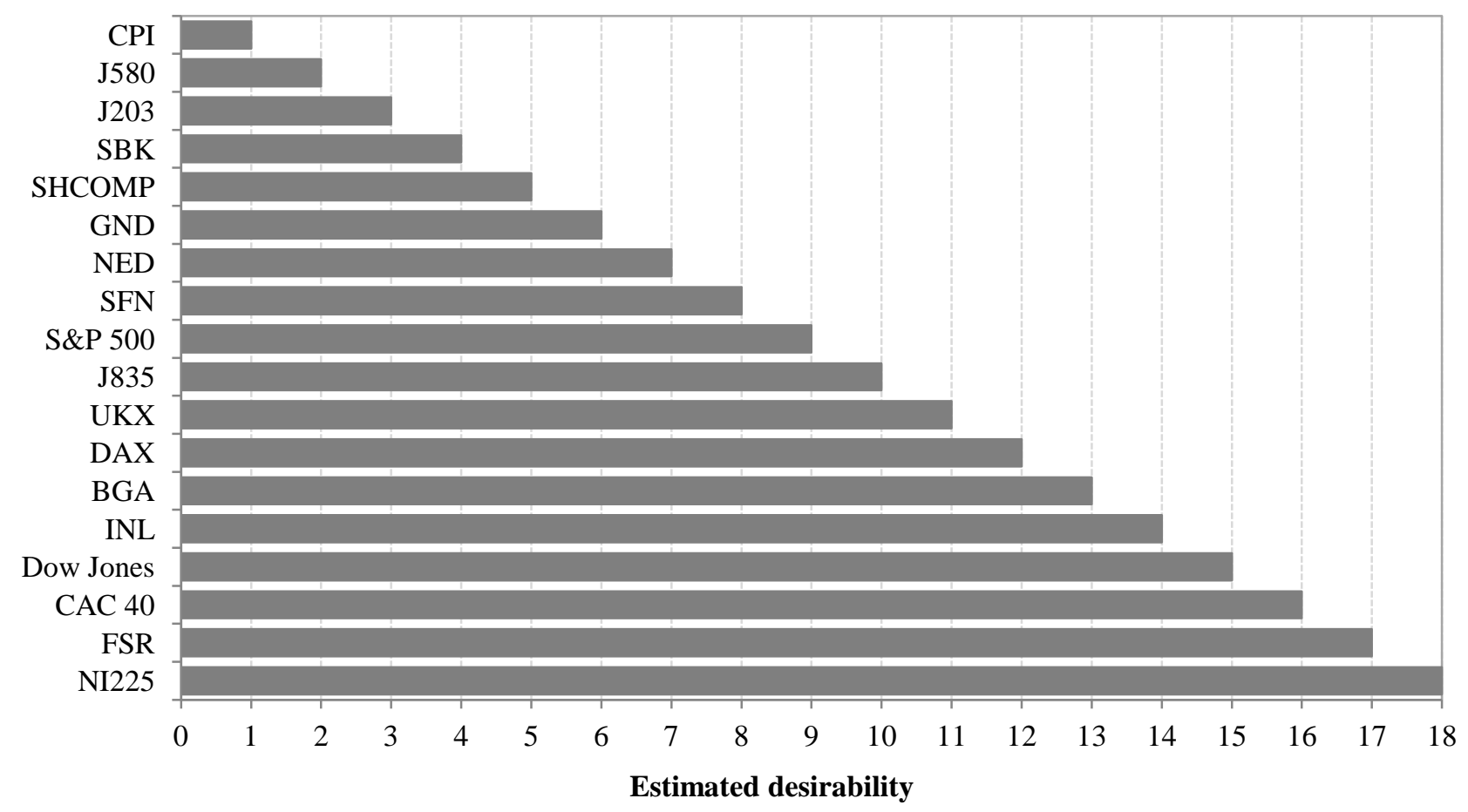

Note: The estimated desirability is based on a combined evaluation of the SC adjusted Sharpe ratio and the Omega ratio. 18 represents the most desirable investment and 1 the least desirable.

Note: Barclays African Group (BGA), FirstRand Limited (FSR), Investec Limited (INL), Nedbank Group Limited (NED), the Standard Bank Group Limited (SBK), African Bank Investments Limited (ABL), Capitec Bank Holdings Limited (CPI), Grindrod Limited (GND), Sasfin Holdings Limited (SFN), the JSE Bank index (J835), the JSE Financial index (J580), the JSE All Share index (J203), the Dow Jones, the S\&P 500, the CAC 40, the DAX, the FTSE 100 index (UKX), the Nikkei 225 index (NI225), and the Shanghai Composite index (SHCOMP) are evaluated.

Source: Compiled by author.

Figure 6: Risk-Adjusted Performance Rankings Based On The Out-Of-Sample Forecasts: Combined Overlook.

Overall, by combining the rankings of the SC adjusted Sharpe ratio and the Omega ratio over the three forecast ranges, it can be argued that the performance of the South African banks is expected to decreased compared to the findings reported in Table 3, 4 and 5. From Figure 6 the combined forecast performance suggests that CPI and SBK will perform the worst of all the South African banks. Although, from the combined results it is expected that FSR will be the best performing bank (ranked second), followed by INL (ranked fifth) and BGA (ranked sixth), respectively. Also, based on Figure 6, these three banks are expected to outperform world indices, such as the DAX, UKX, and S\&P 500. These findings, therefore, suggest that although the South African banking shares decreased in performance due to uncertainty, generated largely by Moody's downgrade, some of these shares still have the possibility to perform relatively well against common world indices. These findings thus emphasise the argument that some South African banking shares can still be considered as relatively competitive and should still be considered as feasible investment options.

\section{CONCLUSION}

Due to several failures that where highlighted by the global financial crisis, the Basel Committee on Banking Supervision (BCBS) introduced the Basel III Accord to enhance the financial landscape in terms of complexity, interdependency, supervision and dynamism that may contain further economic failures. However, the Basel III Accord will place strain on the bank in terms of performance and profitability, which in turn will cause negative investor sentiment to develop for common banking shares. Also, due to Moody's announcement to downgrade CPI and the four major South African banks may further escalate the uncertainty regarding South African banking shares' competitive performance abilities. 
By adapting the Kalman filter as a suitable forecasting tool, performance prognoses were generated of expectations pertaining to South African bank shares over the next 6,12 and 24 months after the downgrade in August 2014. From the forecast returns, generated by the Kalman filter, the Sharpe and Omega ratios were consulted to determine the possible future performance of the South African banks. Overall, the forecast performance evaluation suggests there will be a significant decrease in risk-adjusted performance. Findings suggested that CPI and SBK will perform the worst of all the South African banking shares. Further evidence also suggested that world indices such as NI225, CAC 40, and Dow Jones will outperform most of the South African banking shares. Nonetheless, results were found which suggest that the South African bank index will recover and will be able to outperform the JSE All Share index and the JSE Financial index in two years. Also, from combined results it is expected that FSR will be the best performing South African bank, followed by INL and BGA, respectively. These three banks are also expected to outperform world indices, such as DAX, UKX, and S\&P 500.

Overall, these findings encourage the restoration of future investor sentiment in the banking industry. It also suggest that although the South African banking shares decreased in performance due to greater uncertainty, generated largely by Moody's downgrade, some of these shares still have the possibility to perform relatively well against common world indices. This emphasises the argument that some South African banking shares can still be considered relatively competitive and should be considered as feasible investment options.

To conclude, with South Africa's highly rated financial system and its leading role in bank supervision and regulations, South African banking shares should be considered as desirable, stable investment options. However, the small size of the JSE market can still make it vulnerable to different hedging strategies, like short positions, which can influence the performance of these banking shares, making it an interesting topic for future studies. Also, as pointed out by Brigham and Ehrhard (2005), there remains some doubt about the concept of a risk-free rate, which can further influence the future estimations of performance measures, like the Sharpe ratio, making it an important topic to investigate.

\section{AUTHOR INFORMATION}

\section{Chris van Heerden}

After completing his Masters in finance in 2008, Chris van Heerden was appointed as lecturer at the School of Economics, Potchefstroom Campus, North West University. Soon after he completed his $\mathrm{PhD}$ in finance in 2011, he was promoted to senior lecturer and is currently Program Head of Economics. Email: chris.vanheerden@nwu.ac.za (Corresponding author)

\section{Gary van Vuuren}

Gary van Vuuren completed a Masters in astrophysics and $\mathrm{PhD}$ in nuclear physics through the University of Natal, Durban, worked at the Atomic Energy Corporation and then underwent a short stint at Goldman Sachs in London. $\mathrm{He}$ then obtained a Masters in market risk and a PhD in credit risk through North West University and worked as a risk manager for South African banks and asset managers. He then moved to London and worked as a risk manager for several retail and investment banks before settling on risk assessment and regulatory compliance in financial institutions for Fitch Ratings, where he remains employed. He is an accredited GARP Financial Risk Manager. Email: vvgary@ hotmail.com

\section{REFERENCES}

ABSA. (2013). Origin. Retrieved from http://www.absa.co.za/Absacoza/About-Absa/Absa-Group/Absa-Overview. Akinboade, O.A. \& Makina, D. (2006). Financial sector development in South Africa, 1997-2002. Studies in economics and econometrics, 30(1) 101-127.

Amenc, N., Martellini, L. \& Sfeir, D. (2004). Methodology applied for the AGEFI asset management awards. Edhec risk and asset management research centre. Retrieved from http://www.edhecrisk.com/features/Agefi\%20Awards\%202004/attachments/Agefi\%20Awards\%20Methodology\%20051104. pdf.

Amin, G.S. \& Kat, H.M. (2003). Hedge fund performance 1990-2000: Do the money machines really add value? Journal of financial and quantitative analysis, 38(2) 251-274. 
Bernardo, A.E. \& Ledoit, O. (2000). Gain, loss and asset pricing. Journal of political economy, 108(1) 144-172.

Bianco, K.M. (2008). The subprime lending crisis: Causes and effects of the mortgage meltdown. CCH mortgage compliance guide and bank digest. Retrieved from http://business.cch.com/images/banner/subprime.pdf.

BIS (Bank for International Settlements). (2011). Basel III: A global regulatory framework for more resilient banks and banking systems. Retrieved from http://www.bis.org/publ/bcbs189.pdf.

Blundell-Wignall, A., Atkinson, P. \& Lee, S.H. (2008). The current financial crisis: Causes and policy issues. OECD Journal: Financial market trends, 10 1-21.

Botha, M. (2007). A comparison of South African hedge fund risk measures. South African journal of economics, 75(3) 459-477.

Brigham, E.F. \& Ehrhardt, M.C. (2005). Financial Management: Theory and practice, $11^{\text {th }}$ Edition. Mason, Ohio: Thomson South-Western.

Brooks, R.D., Faff, R.W. \& McKenzie, M.D. (1998). Time-varying beta risk of Australian industry portfolio: A comparison of modelling techniques. Australian journal of management, 23(1) 1-22.

Chu, C.-S.J. \& Stinchcombe, M. \& White, H. (1996). Monitoring structural change. Econometrica, 64(5) 10451065.

Copeland, T., Koller, T. \& Murrin, J. (2000). Valuation: Measuring and managing the value of companies, $3^{\text {rd }}$ Edition. New York: Wiley.

Das, S., Kadapakkam, P-R. \& Tse, Y. (2013). Is carry-trade a viable alternative asset class? Journal of international financial markets, institutions and money, 24(April) 247-257.

Davies, R.J., Kat, H.M. \& Lu, S. (2009). Fund of hedge funds portfolio selection: A multiple objective approach. Journal of derivatives and hedge funds, 15(2) 91-115.

De Wet, J. (2005). EVA versus traditional accounting measures of performance as drivers of shareholders value - a comparative analysis. Meditari: Research Journal of the School of Accounting Sciences, 13(2) 1-16.

De Wet, R., Krige, J.D. \& Smit, E. vd M. (2008). An investigation into performance rankings of the Omega ratio vs. the Sharpe ratio applied to South African general equity unit trusts. Journal of studies in economics and econometrics, 32(2) 69-83

Faff, R. W., Hillier, D. \& Hillier, J. (2000). Time varying $\beta$ risk: An analysis of alternative modelling techniques, Journal of Business Finance and Accounting, 27(5-6) 523-554.

Favre, L. \& Galeano, J.A. (2002). Mean-Modified Value at Risk with hedge funds. The journal of alternative investments, 5(2) 21-25.

Favre-Bulle, A. \& Pache, S. (2003). The Omega measure: Hedge fund portfolio optimization. University of Lausanne. Retrieved from http://www.edge-fund.com/FBPa03.pdf.

Ferhani, H. J. \& Sayeh, A. M. (2008). Financial system stability assessment. International Monetary Fund, South Africa. IMF country report no. 08/349. Retrieved from http://www.imf.org/external/pubs/ft/scr/2008/ cr08349.pdf.

Fin24. (2013). Abil plunges on bad loans. Retrieved from http://www.fin24.com/Companies/FinancialServices/Abil-plunges-on-bad-loans-20131111.

Fin24. (2013a). Absa takeover a done deal. Retrieved from http://www.fin24.com/Companies/Absa-takeover-adone-deal-20050707.

Fin24. (2014). Moody's cuts ratings of four more top banks. Retrieved from http://www.fin24.com/Companies/Financial-Services/Moodys-cuts-ratings-of-four-more-top-bank20140819.

Fin24. (2014a.) SA bank index down after Moody's downgrade. Retrieved from http://www.fin24.com/Companies/Financial-Services/SA-bank-index-down-after-Moodys-downgrade20140820.

Fin24. (2014b). Capitec slams Moody's downgrade. Retrieved from http://www.fin24.com/Companies/FinancialServices/Capitec-slams-Moodys-downgrade-20140818.

First National Bank (FNB). (2014). The FirstRand Group. Retrieved from https://www.fnb.co.za/about-fnb/firstrand-group.html.

Fung, W. \& Hsieh, D.A. (1999). A primer on hedge funds. Journal of empirical finance, 6(3) 309-331.

Gatfaoui, H. 2012. A correction for classic performance measures. Chinese business review, 1(1) 1-28.

GFD (Global Financial Development Report). (2013). The role of the state in promoting bank competition. Retrieved from http://siteresources.worldbank.org/EXTGLOBALFINREPORT/Resources/88160961346865433023/8827078-1346865457422/Chapter-3.pdf. 
Gilli, M., Schumann, E., Di Tollo, G. \& Cabej, G. (2011). Constructing 130/30-portfolios with the Omega ratio. Journal of asset management, 12(2) 94-108.

Gregoriou, G.N. \& Gueyie, J-P. (2003). Risk-adjusted performance of funds of hedge funds using a Modified Sharpe ratio. Journal of wealth management, 6(3) 77-83.

Grewal, M.S. \& Andrews, A.P. (2001). Kalman Flitering: Theory and practice using MATLAB, $2^{\text {nd }}$ Edition. New York: John Wiley \& Sons, Inc.

Harding, D. (2002). A critique of the Sharpe Ratio. Retrieved from http://michaelcovel.com/pdfs/Hard02.pdf.

Härle, P., Lüders, E., Pepanides, T., Poppensieker, T. \& Stegemann, U. (2010). Basel III and European banking: Its impact, how banks might respond, and the challenges of implementation. McKinsey working papers on risk, no. 26, EMEA Banking. Retrieved from http://www.mckinsey.com/ /media/mckinsey/dotcom/ client_service/Risk/Working\%20papers/26_Basel_III_and_European_banking.ashx.

Harlow, W.V. (1991). Asset allocation in a downside-risk framework. Financial analysts journal, 47(5) 28-40.

Hawkins, P. (2004). South Africa's financial sector ten years on: Performance since democracy. Development South Africa, 21(1) 179-204.

Heider, F., Hoerova, M. \& Holthausen, C. (2009). Liquidity hoarding and interbank market spreads. The role of counterparty risk. European Central Bank, working paper series, no 1126 / December 2009. Retrieved from http://www.ecb.europa.eu/pub/pdf/scpwps/ecbwp1126.pdf.

Hentati, R., Kaffel, A. \& Prigent, J-L. (2010). Dynamic versus static optimization of hedge fund portfolios: The relevance of performance measures. International journal of business, 15(1) 1-17.

Hwang, S. \& Pedersen, C.S. (2004). Asymmetric risk measures when modelling emerging markets equities: Evidence for regional and timing effects. Emerging markets review, 5(1) 109-128.

Inoue, A. (2001). Testing for distributional change in time series. Econometric theory, 17(1) 156-187.

International Business Machines Corporation (IBM). (2013). SPPS Statistics, version 22 program.

Kalman, R.E. (1960). A new approach of linear filtering and prediction problems. Transaction of the ASMEJournal of Basic Engineering, 82(1) 35-45.

Kat, H.M. (2003). 10 Things investors should know about hedge funds. The Journal of wealth management, 5(4) 7281.

Kazemi, H., Schneeweis, T. \& Gupta, R. (2003). Omega as a performance measure. Working paper, 6-15-03. Retrieved from http://www.edge-fund.com/KaSG03.pdf.

Keating, C. \& Shadwick, W.F. (2002). A universal performance measure. Journal of performance measurement, 6(3) 59-84.

Koch, W. (2006). Advanced target tracking techniques. In Advanced Radar Signal and Data Processing, Educational Notes RTO-EN-SET-086, Paper 2, Neuilly-sur-Seine, France, 2-1-2-34. Retrieved from http://www.google.co.za/url?sa=t\&rct=j\&q=\&esrc=s\&source=web\&cd=1\&ved=0CCEQFjAA\&url=http $\% 3$ A\%2F\%2Fwww.dtic.mil\%2Fcgi-bin\%2FGetTRDoc\%3FAD\%3DADA470657\&ei=vLo_ VN3GLOHC7gavuYHoBw\&usg=AFQjCNFae4tArw59EvLAXXLmWPnJBNDWqA

KPMG. (2011). Basel III: Issues and implications. Retrieved from http://www.kpmg.com/global/en/ issuesandinsights/ articlespublications/documents/basell-iii-issues-implications.pdf.

Krokhmal, P., Palmquist, J. \& Uryasev, S. (2002). Portfolio optimization with Conditional Value-At-Risk objective and constraints. Journal of risk, 4(2) 43-68.

Lamm, R.M. (2003). Asymmetric returns and optimal hedge fund portfolios. Journal of alternative investments, 6(2) $9-21$.

Lhabitant, F. 2004. Hedge funds: Quantitative insight. Haboken, NJ: Wiley.

Liang, B. \& Park, H. (2007). Risk measures for hedge funds: A cross-sectional approach. European financial management, 13(2) 333-370.

Lo, A. W. (2002). The statistics of Sharpe ratios. Financial Analysts Journal, 58(4) 36-52.

Makridakis, S., Wheelwright, S.C. \& Hyndman, R.J. (1998). Forecasting: Method and applications, $3^{\text {rd }}$ Edition. New York: John Wiley \& Sons.

Markowitz, H. (1952). Portfolio selection. Journal of finance, 7(1) 77-91.

McGregor BFA database. (2014). Supplier of data. Retrieved from https://expert.mcgregorbfa.com/.

Moolman, E. \& Du Toit, C. (2005). An econometric model of the South African stock market. South African Journal of Economic and Management Sciences, 8(1) 77-91.

National Treasury. (2011). A safer financial sector to serve South Africa better. National Treasury policy document, South Africa. Retrieved from http://www.treasury.gov.za/documents/national\%20budget/ 
2011/A\%20safer\%20financial\%20sector\%20to\%20serve\%20South\%20Africa\%20better.pdf

Nedbank. (2014). Nedbank Group History. Retrieved from http://www.nedbankgroup.co.za/aboutHistory.asp.

Ozcan, Y.A. (2009). Quantitative methods in health care management: Techniques and applications, $2^{\text {nd }}$ Edition. San Francisco: Jossey-Bass.

Price Waterhouse Coopers (PwC). (2013). Finding strength in adversity: South Africa- major banks analysis. Retrieved from http://www.pwc.co.za/en/assets/pdf/banking-analysis-september2013.pdf.

Price Waterhouse Coopers (PwC). (2013a). Shaping the bank of the future: South African banking survey 2013. Retrieved from http://www.pwc.co.za/en_ZA/za/assets/pdf/south-african-banking-survey-2013.pdf.

Punales, A.G.S. (2011). Time-varying coefficient model and the Kalman filter: Applications to hedge funds. Retrieved from http://digital.library.ryerson.ca/islandora/object/RULA\%3A2193.

QMS (Quantitative Micro Software). (2009). EViews user guide 1.

Reschenhofer, E. (1997). Generalization of the Kolmogorov-Smirnov test. Computational statistics \& data analysis, 24(4) 433-441.

Reschenhofer, E. (2004). Unexpected features of financial time series: Higher-order anomalies and predictability. Journal of data science, 2(1) 1-15.

Ribeiro, M.I. (2004). Kalman and extended Kalman filters: Concept, deviation and properties. Retrieved from http://users.isr.ist.utl.pt/ mir/pub/kalman.pdf.

SARB (South African Reserve Bank). (2010). Financial stability review, September 2010. South African Reserve Bank. Retrieved from https://www.resbank.co.za/Lists/News\%20and\%20Publications/ Attachments/3953/FSR+Sept2010.pdf.

SARB (South African Reserve Bank). (2011). Financial stability review, September 2011. South African Reserve Bank. Retrieved from https://www.resbank.co.za/Lists/News\%20and\%20Publications/Attachments/ 865/FSR\%20September\%202011.pdf.

SARB (South African Reserve Bank). (2012). Financial stability review, September 2011. South African Reserve Bank. Retrieved from https://www.resbank.co.za/Lists/News\%20and\%20Publications/Attachments/ 5194/FSR\%20Sept\%202012_2.pdf.

SARB (South African Reserve Bank). (2013). Financial stability review, March, 2013. South African Reserve Bank. Retrieved from https://www.resbank.co.za/Lists/News\%20and\%20Publications/Attachments/ 5679/FSR\%20March\%202013(1).pdf.

SARB (South African Reserve Bank). (2013a). South Africa's implementation of Basel II and Basel III. Retrieved from http://www.resbank.co.za/RegulationAndSupervision/BankSupervision/TheBasel CapitalAccord\%28Basel\%20II\%29/Pages/AccordImplementationForum\%28AIF\%29.aspx.

SARB (South African Reserve Bank). (2014). Financial stability review, March, 2014. South African Reserve Bank. Retrieved from https://www.resbank.co.za/Lists/News\%20and\%20Publications/Attachments/ 6204/FSR\%20March\%202014.pdf.

SARB (South African Reserve Bank). (Various years: 2003-2013). Financial stability review. South African Reserve Bank. Retrieved from https://www.resbank.co.za/Publications/Reviews/Pages/ FinancialStabilityReview.aspx.

Sharpe, W. (1966). Mutual fund performance. Journal of business, 39(1) 119-138.

Sharpe, F.A. (1994). The Sharpe ratio. Journal of portfolio management, 21(1) 49-58.

Sortiono, F.A. \& Prince, L. (1994). Performance measurement in a downside risk framework. Journal of investing, 3(3) 59-64.

Sowell, F. (1996). Optimal tests for parameter instability in the generalized method of moments framework. Econometrica, 64(5) 1085-1107.

Standard Bank. (2014). History. Retrieved from http://www.standardbank.com/Highlights.aspx.

The Banking Association of South Africa. (2010). South African banking industry overview. The banking association of South Africa, September 2010.

The Banking Association of South Africa. (2011). South African banking industry overview. The banking association of South Africa, November 2011.

The Banking Association of South Africa. (2012). 2012 South African banking industry overview. Retrieved from http://www.banking.org.za/index.php/our-industry/2012-south-african-banking-sector-overview/.

Togher, S. \& Barsbay, T. (2007). Fund of hedge funds portfolio optimization using the Omega ratio. Risk mangement/Compliance. Retrieved from http://www.imca.org/publication-issues/julyaugust2007\%E2\%80\%94risk-managementcompliance. 
Tsay, R.S. (2010). Analysis of financial time series, $3^{\text {rd }}$ Edition. New York: John Wiley \& Sons.

Van Dyk, F., Van Vuuren, G. \& Heymans, A. (2014). Hedge fund performance using scaled Sharpe and Treynor measures. International business \& economic research journal, forthcoming.

Welch, G. \& Bishop, G. (2006). An introduction to the Kalman filter. Retrieved from http://www.cs.unc.edu/ welch/kalman/kalmanIntro.html.

Wong, W-K., Phoon, K. F., \& Lean, H. H. (2008). Stochastic dominance analysis of Asian hedge funds. PacificBasin finance journal, 16(3) 204-223.

Yahoo Finance. (2014). Supplier of data. Retrieved from http://finance.yahoo.com/.

Young, T.W. (1991). Calmar ratio: A smoother tool. Futures, 20(1) 40. 


\section{APPENDIX}

Table A: Monthly Return Performance Comparison (\%): January 2003 To August 2014.

PRE-FINANCIAL CRISIS PERIOD

\begin{tabular}{|c|c|c|c|c|c|c|c|c|c|c|c|c|c|c|c|}
\hline \multicolumn{8}{|c|}{ PRE-FINANCIAL CRISIS PERIOD } & \multicolumn{8}{|c|}{ POST-FINANCIAL CRISIS PERIOD } \\
\hline \multicolumn{2}{|c|}{ Average Returns } & \multicolumn{2}{|c|}{$\begin{array}{c}\text { Cumulative } \\
\text { Returns }\end{array}$} & \multicolumn{2}{|c|}{$\begin{array}{c}\text { Standard } \\
\text { Deviation } \\
\end{array}$} & \multicolumn{2}{|c|}{$\begin{array}{l}\text { Risk-Adjusted } \\
\text { Returns }\end{array}$} & \multicolumn{2}{|c|}{ Average Returns } & \multicolumn{2}{|c|}{$\begin{array}{c}\text { Cumulative } \\
\text { Returns }\end{array}$} & \multicolumn{2}{|c|}{$\begin{array}{l}\text { Standard } \\
\text { Deviation }\end{array}$} & \multicolumn{2}{|c|}{$\begin{array}{c}\text { Risk-Adjusted } \\
\text { Returns }\end{array}$} \\
\hline $\mathrm{CPI}$ & 0.30 & CPI & 94.87 & J580 & 16.26 & GND & 266.49 & CPI & 0.10 & CPI & 23.78 & $\mathrm{~J} 580$ & 14.55 & S\&P 500 & 120.26 \\
\hline GND & 0.26 & GND & 83.59 & J203 & 17.16 & CPI & 211.80 & S\&P 500 & 0.09 & S\&P 500 & 22.81 & J203 & 14.95 & Dow Jones & 113.44 \\
\hline SFN & 0.21 & SFN & 60.92 & FTSE 100 & 21.01 & J580 & 179.75 & FSR & 0.09 & FSR & 20.46 & FTSE 100 & 17.64 & $\mathrm{~J} 580$ & 108.02 \\
\hline $\mathrm{ABL}$ & 0.19 & $\mathrm{ABL}$ & 50.48 & S\&P 500 & 21.85 & SFN & 178.81 & Dow Jones & 0.08 & Dow Jones & 20.41 & Dow Jones & 17.99 & $\mathrm{CPI}$ & 103.04 \\
\hline INL & 0.16 & BGA & 41.45 & Dow Jones & 21.87 & $\mathrm{~J} 203$ & 164.74 & DAX & 0.07 & DAX & 17.27 & S\&P 500 & 18.97 & $\mathrm{~J} 203$ & 93.86 \\
\hline BGA & 0.15 & INL & 40.75 & CAC 40 & 22.86 & BGA & 163.47 & INL & 0.06 & J580 & 15.71 & J835 & 19.97 & FSR & 82.11 \\
\hline SBK & 0.13 & SBK & 33.36 & J835 & 23.27 & $\mathrm{ABL}$ & 150.44 & NED & 0.06 & FTSE 100 & 14.40 & DAX & 21.37 & FTSE 100 & 81.68 \\
\hline FSR & 0.13 & FSR & 32.08 & DAX & 24.94 & J835 & 137.11 & J580 & 0.06 & NED & 14.09 & SBK & 22.06 & DAX & 80.83 \\
\hline J835 & 0.12 & J835 & 31.91 & BGA & 25.35 & INL & 127.29 & FTSE 100 & 0.06 & $\mathrm{~J} 203$ & 14.04 & CAC 40 & 22.68 & J835 & 66.74 \\
\hline J580 & 0.11 & J580 & 29.23 & SBK & 27.19 & SBK & 122.70 & J835 & 0.06 & INL & 13.67 & CPI & 23.07 & NED & 60.63 \\
\hline J203 & 0.11 & J203 & 28.27 & NI225 & 27.57 & FSR & 114.79 & $\mathrm{~J} 203$ & 0.06 & J835 & 13.32 & NED & 23.24 & INL & 55.03 \\
\hline NI225 & 0.10 & NI225 & 23.90 & FSR & 27.95 & NI225 & 86.72 & CAC 40 & 0.04 & CAC 40 & 8.75 & BGA & 23.47 & CAC 40 & 38.58 \\
\hline DAX & 0.09 & SHCOMP & 22.79 & SHCOMP & 28.33 & DAX & 86.35 & GND & 0.04 & GND & 7.39 & SHCOMP & 24.68 & SBK & 30.27 \\
\hline CAC 40 & 0.07 & DAX & 21.54 & NED & 28.95 & SHCOMP & 80.44 & SFN & 0.04 & SBK & 6.68 & GND & 24.74 & GND & 29.85 \\
\hline FTSE 100 & 0.05 & CAC 40 & 16.70 & GND & 31.37 & CAC 40 & 73.08 & SBK & 0.04 & SFN & 6.35 & INL & 24.84 & SFN & 24.12 \\
\hline S\&P 500 & 0.04 & FTSE 100 & 12.00 & INL & 32.01 & FTSE 100 & 57.10 & BGA & 0.03 & BGA & 5.64 & FSR & 24.91 & BGA & 24.02 \\
\hline NED & 0.04 & S\&P 500 & 7.05 & $\mathrm{ABL}$ & 33.56 & S\&P 500 & 32.25 & NI225 & 0.03 & NI225 & 2.63 & SFN & 26.34 & NI225 & 8.10 \\
\hline Dow Jones & 0.03 & Dow Jones & 5.02 & SFN & 34.07 & Dow Jones & 22.95 & SHCOMP & -0.06 & SHCOMP & -16.93 & NI225 & 32.51 & SHCOMP & -68.59 \\
\hline SHCOMP & 0.10 & NED & 4.74 & CPI & 44.79 & NED & 16.36 & $\mathrm{ABL}$ & -0.25 & $\mathrm{ABL}$ & -62.79 & $\mathrm{ABL}$ & 63.43 & ABL & -98.99 \\
\hline
\end{tabular}


(Table A continued)

\begin{tabular}{|c|c|c|c|c|c|c|c|c|c|c|c|c|c|c|c|}
\hline \multicolumn{8}{|c|}{ DURING FINANCIAL CRISIS PERIOD } & \multicolumn{8}{|c|}{ DURING FINANCIAL CRISIS PERIOD } \\
\hline \multicolumn{2}{|c|}{ Average Returns } & \multicolumn{2}{|c|}{$\begin{array}{c}\begin{array}{c}\text { Cumulative } \\
\text { Returns }\end{array} \\
\end{array}$} & \multicolumn{2}{|c|}{\begin{tabular}{ll|} 
Standard \\
Deviation
\end{tabular}} & \multicolumn{2}{|c|}{$\begin{array}{c}\text { Risk-Adjusted } \\
\text { Returns }\end{array}$} & \multicolumn{2}{|c|}{ Average Returns } & \multicolumn{2}{|c|}{$\begin{array}{c}\text { Cumulative } \\
\text { Returns }\end{array}$} & \multicolumn{2}{|c|}{$\begin{array}{c}\text { Standard } \\
\text { Deviation }\end{array}$} & \multicolumn{2}{|c|}{$\begin{array}{l}\text { Risk-Adjusted } \\
\text { Returns }\end{array}$} \\
\hline $\mathrm{CPI}$ & 0.13 & CPI & 30.1 & Dow Jones & 22.9 & CPI & 81.0 & CPI & 0.18 & CPI & 46.5 & J580 & 19.0 & CPI & 131.1 \\
\hline GND & 0.06 & GND & 4.5 & S\&P 500 & 24.1 & $\mathrm{~J} 203$ & 13.0 & GND & 0.12 & GND & 28.2 & $\mathrm{~J} 203$ & 20.0 & GND & 85.1 \\
\hline SHCOMP & 0.04 & $\mathrm{~J} 203$ & 3.6 & J580 & 26.7 & GND & 10.1 & SFN & 0.10 & SFN & 21.5 & Dow Jones & 20.7 & J203 & 80.5 \\
\hline $\mathrm{ABL}$ & 0.04 & SFN & 2.7 & FTSE 100 & 27.2 & SFN & 7.4 & FSR & 0.08 & FSR & 16.6 & S\&P 500 & 21.4 & J580 & 74.4 \\
\hline SBK & 0.04 & SBK & 2.6 & DAX & 27.3 & SBK & 6.7 & BGA & 0.07 & $\mathrm{~J} 203$ & 15.8 & FTSE 100 & 21.6 & SFN & 67.1 \\
\hline SFN & 0.04 & DAX & 1.4 & J203 & 27.6 & DAX & 5.3 & INL & 0.07 & J835 & 15.8 & DAX & 24.3 & J835 & 60.9 \\
\hline BGA & 0.03 & $\mathrm{ABL}$ & 1.4 & CAC 40 & 28.5 & $\mathrm{ABL}$ & 3.3 & J835 & 0.07 & BGA & 15.4 & CAC 40 & 24.4 & DAX & 59.2 \\
\hline J203 & 0.03 & BGA & 0.9 & J835 & 35.5 & BGA & 2.3 & SBK & 0.07 & DAX & 14.4 & J835 & 25.9 & FSR & 53.7 \\
\hline J835 & 0.03 & J835 & 0.5 & SFN & 36.9 & J835 & 1.4 & $\mathrm{~J} 203$ & 0.07 & J580 & 14.1 & BGA & 28.7 & BGA & 53.6 \\
\hline DAX & 0.02 & SHCOMP & 0.4 & CPI & 37.2 & SHCOMP & 0.8 & DAX & 0.07 & SBK & 14.0 & SBK & 29.0 & SBK & 48.3 \\
\hline NED & 0.02 & NED & -2.4 & BGA & 38.7 & NED & -6.2 & J580 & 0.06 & INL & 13.3 & NED & 29.9 & S\&P 500 & 43.7 \\
\hline FSR & 0.01 & Dow Jones & -4.1 & NED & 39.1 & FSR & -15.1 & S\&P 500 & 0.05 & S\&P 500 & 9.3 & FSR & 30.9 & Dow Jones & 40.4 \\
\hline Dow Jones & -0.01 & J580 & -5.4 & SBK & 39.1 & Dow Jones & -17.8 & NED & 0.04 & Dow Jones & 8.4 & SFN & 32.1 & INL & 39.4 \\
\hline J580 & -0.01 & S\&P 500 & -6.1 & FSR & 41.2 & J580 & -20.3 & Dow Jones & 0.04 & CAC 40 & 7.1 & SHCOMP & 32.7 & FTSE 100 & 32.8 \\
\hline CAC 40 & -0.01 & FSR & -6.2 & $\mathrm{ABL}$ & 42.7 & CAC 40 & -23.4 & CAC 40 & 0.04 & FTSE 100 & 7.1 & GND & 33.1 & CAC 40 & 29.2 \\
\hline S\&P 500 & -0.01 & CAC 40 & -6.7 & GND & 44.5 & S\&P 500 & -25.2 & FTSE 100 & 0.04 & NED & 6.4 & INL & 33.9 & NED & 21.4 \\
\hline FTSE 100 & -0.02 & FTSE 100 & -8.9 & SHCOMP & 46.3 & FTSE 100 & -32.9 & NI225 & 0.03 & NI225 & 1.6 & CPI & 35.5 & NI225 & 4.2 \\
\hline INL & -0.02 & INL & -15.4 & INL & 46.3 & INL & -33.3 & SHCOMP & 0.02 & SHCOMP & -0.3 & NI225 & 37.5 & SHCOMP & -0.8 \\
\hline NI225 & -0.05 & NI225 & -23.3 & NI225 & 53.1 & NI225 & -43.8 & $\mathrm{ABL}$ & -0.03 & $\mathrm{ABL}$ & -22.2 & $\mathrm{ABL}$ & 49.7 & $\mathrm{ABL}$ & -44.7 \\
\hline
\end{tabular}

Note: Each is ranked from best to worst.

Note: A comparison of Barclays African Group (BGA), FirstRand Limited (FSR), Investec Limited (INL), Nedbank Group Limited (NED), the Standard Bank Group Limited (SBK), African Bank Investments Limited (ABL), Capitec Bank Holdings Limited (CPI), Grindrod Limited (GND), Sasfin Holdings Limited (SFN), the JSE Bank index (J835), the JSE Financial index (J580), the JSE All Share index (J203), the Dow Jones, the S\&P 500, the CAC 40, the DAX, the FTSE 100 index (UKX), the Nikkei 225 index (NI225), and the Shanghai Composite index (SHCOMP) is provided above.

Source: The data were obtained from Yahoo Finance (2014) for the world indices and from the McGregor BFA (2014) database for the South African indices and shares. 
Table B: Risk-Adjusted Performance Rankings Based On The 6-Month Out-Of Sample Forecast

RANKINGS BASED ON 6-MONTH FORECAST (SEPTEMBER 2014 TO FEBRUARY 2015)

\begin{tabular}{|c|c|c|c|c|c|c|c|c|c|c|c|c|}
\hline \multicolumn{2}{|c|}{ Traditional Sharpe } & \multicolumn{2}{|c|}{ SC Sharpe } & \multicolumn{2}{|c|}{ Sharpe $S^{*}$} & \multicolumn{2}{|c|}{ SC Sharpe $S^{*}$} & \multicolumn{2}{|c|}{ Sharpe $S^{* *}$} & \multicolumn{2}{|c|}{ SC Sharpe $\mathbf{S}^{* *}$} & \multirow{2}{*}{$\begin{array}{c}\text { Omega } \\
\text { Rank } \\
\end{array}$} \\
\hline Rank & Est. & Rank & Est. & Rank & Est. & Rank & Est. & Rank & Est. & Rank & Est. & \\
\hline NI225 & $>5$ & NI225 & $>5$ & GND & - & GND & - & GND & - & GND & - & BGA \\
\hline S\&P 500 & $>5$ & S\&P 500 & $>5$ & INL & - & INL & - & INL & - & INL & - & Dow Jones \\
\hline INL & $>5$ & INL & $>5$ & $\mathrm{~J} 203$ & - & $\mathrm{J} 203$ & - & $\mathrm{J} 203$ & - & J203 & - & FSR \\
\hline UKX & $>5$ & UKX & $>5$ & CAC 40 & - & CAC 40 & - & CAC 40 & - & CAC 40 & - & CAC 40 \\
\hline Dow Jones & $>5$ & Dow Jones & $>5$ & DAX & - & DAX & - & DAX & - & DAX & - & NI225 \\
\hline DAX & $>5$ & DAX & $>5$ & UKX & - & UKX & - & UKX & - & UKX & - & NED \\
\hline CAC 40 & $>5$ & CAC 40 & $>5$ & SHCOMP & 0.15 & SHCOMP & 0.15 & J580 & $>5$ & J580 & $>5$ & SBK \\
\hline BGA & $>5$ & BGA & $>5$ & CPI & 0.02 & CPI & 0.02 & S\&P 500 & $>5$ & S\&P 500 & $>5$ & SFN \\
\hline GND & $>5$ & GND & $>5$ & SFN & -0.02 & SFN & -0.02 & NI225 & $>5$ & NI225 & $>5$ & J835 \\
\hline $\mathrm{J} 580$ & $>5$ & J580 & $>5$ & Dow Jones & -0.03 & Dow Jones & -0.03 & BGA & $>5$ & BGA & $>5$ & DAX \\
\hline FSR & $>5$ & FSR & $>5$ & BGA & -0.11 & BGA & -0.11 & FSR & $>5$ & FSR & $>5$ & INL \\
\hline J203 & $>5$ & J203 & $>5$ & FSR & -0.12 & FSR & -0.12 & NED & $>5$ & NED & $>5$ & GND \\
\hline J835 & 4.70 & J835 & 4.70 & S\&P 500 & -0.13 & S\&P 500 & -0.13 & J835 & $>5$ & J835 & $>5$ & UKX \\
\hline SFN & 3.43 & SFN & 3.43 & NI225 & -0.13 & NI225 & -0.13 & Dow Jones & $>5$ & Dow Jones & $>5$ & SHCOMP \\
\hline NED & 2.62 & NED & 2.62 & J580 & -0.14 & J580 & -0.14 & SBK & 4.47 & SBK & 4.47 & CPI \\
\hline SBK & 1.08 & SBK & 1.08 & NED & -0.14 & NED & -0.14 & SFN & 1.44 & SFN & 1.44 & $\mathrm{~J} 203$ \\
\hline SHCOMP & -1.58 & SHCOMP & -1.58 & SBK & -0.16 & SBK & -0.16 & CPI & -1.20 & CPI & -1.20 & S\&P 500 \\
\hline CPI & -4.12 & CPI & -4.12 & J835 & -0.17 & $\mathrm{~J} 835$ & -0.17 & SHCOMP & -6.96 & SHCOMP & -6.96 & J580 \\
\hline
\end{tabular}

Note: Each ranking is from best to worst and "Est." denotes the estimate; Omega ranking entails a combination of the downside and upside ranking. Investment options with "_" estimates represents occurrences where the forecast returns exhibited no downside risk, making the estimation of scaled Sharpe ratios impossible.

Note: Barclays African Group (BGA), FirstRand Limited (FSR), Investec Limited (INL), Nedbank Group Limited (NED), the Standard Bank Group Limited (SBK), African Bank Investments Limited (ABL), Capitec Bank Holdings Limited (CPI), Grindrod Limited (GND), Sasfin Holdings Limited (SFN), the JSE Bank index (J835), the JSE Financial index (J580), the JSE All Share index (J203), the Dow Jones, the S\&P 500, the CAC 40, the DAX, the FTSE 100 index (UKX), the Nikkei 225 index (NI225), and the Shanghai Composite index (SHCOMP) are evaluated.

Source: The data were obtained from Yahoo Finance (2014) for the world indices and from the McGregor BFA (2014) database for the South African indices and shares. 
Table C: Risk-Adjusted Performance Rankings Based On The 12-Month Out-Of-Sample Forecast

\begin{tabular}{|c|c|c|c|c|c|c|c|c|c|c|c|c|}
\hline \multicolumn{13}{|c|}{ RANKINGS BASED ON 12-MONTH FORECAST (SEPTEMBER 2014 TO AUGUST 2015) } \\
\hline \multicolumn{2}{|c|}{ Traditional Sharpe } & \multicolumn{2}{|c|}{ SC Sharpe } & \multicolumn{2}{|c|}{ Sharpe $\mathrm{S}^{*}$} & \multicolumn{2}{|c|}{ SC Sharpe S* } & \multicolumn{2}{|c|}{ Sharpe $\mathrm{S}^{* *}$} & \multicolumn{2}{|c|}{ SC Sharpe $\mathbf{S}^{* *}$} & \multirow{2}{*}{$\begin{array}{c}\text { Omega } \\
\text { Rank }\end{array}$} \\
\hline Rank & Est. & Rank & Est. & Rank & Est. & Rank & Est. & Rank & Est. & Rank & Est. & \\
\hline S\&P 500 & $>5$ & S\&P 500 & $>5$ & CAC 40 & - & CAC 40 & - & CAC 40 & - & CAC 40 & - & FSR \\
\hline Dow Jones & $>5$ & Dow Jones & $>5$ & DAX & - & DAX & - & DAX & - & DAX & - & BGA \\
\hline NI225 & $>5$ & NI225 & $>5$ & UKX & - & UKX & - & UKX & - & UKX & - & NI225 \\
\hline SHCOMP & $>5$ & SHCOMP & $>5$ & GND & - & GND & - & GND & - & GND & - & CAC 40 \\
\hline UKX & $>5$ & UKX & $>5$ & S\&P 500 & - & S\&P 500 & - & S\&P 500 & - & S\&P 500 & - & J835 \\
\hline GND & $>5$ & GND & $>5$ & CPI & 0.01 & CPI & 0.01 & Dow Jones & $>5$ & Dow Jones & $>5$ & NED \\
\hline INL & $>5$ & INL & $>5$ & SFN & -0.03 & SFN & -0.03 & NI225 & $>5$ & NI225 & $>5$ & SFN \\
\hline CAC 40 & $>5$ & CAC 40 & $>5$ & BGA & -0.09 & BGA & -0.09 & INL & $>5$ & INL & $>5$ & DAX \\
\hline DAX & $>5$ & DAX & $>5$ & INL & -0.09 & INL & -0.09 & $\mathrm{~J} 203$ & $>5$ & $\mathrm{~J} 203$ & $>5$ & SBK \\
\hline J580 & $>5$ & J580 & $>5$ & SHCOMP & -0.09 & SHCOMP & -0.09 & SHCOMP & $>5$ & SHCOMP & $>5$ & INL \\
\hline J203 & $>5$ & J203 & $>5$ & NED & -0.09 & NED & -0.09 & J580 & $>5$ & J580 & $>5$ & SHCOMP \\
\hline FSR & 2.36 & FSR & 2.36 & Dow Jones & -0.10 & Dow Jones & -0.10 & FSR & $>5$ & FSR & $>5$ & GND \\
\hline SFN & 1.21 & SFN & 1.21 & J580 & -0.11 & J580 & -0.11 & SFN & 0.86 & SFN & 0.86 & UKX \\
\hline NED & 0.11 & NED & 0.11 & FSR & -0.11 & FSR & -0.11 & NED & 0.43 & NED & 0.43 & CPI \\
\hline J835 & -0.45 & J835 & -0.45 & J835 & -0.12 & J835 & -0.12 & J835 & -1.42 & $\mathrm{~J} 835$ & -1.42 & $\mathrm{~J} 203$ \\
\hline BGA & -0.72 & BGA & -0.72 & $\mathrm{~J} 203$ & -0.12 & $\mathrm{~J} 203$ & -0.12 & BGA & -1.44 & BGA & -1.44 & Dow Jones \\
\hline SBK & -1.80 & SBK & -1.80 & SBK & -0.13 & SBK & -0.13 & CPI & -2.00 & CPI & -2.00 & S\&P 500 \\
\hline CPI & -3.70 & CPI & -3.70 & NI225 & -0.19 & NI225 & -0.19 & SBK & -5.83 & SBK & -5.83 & J580 \\
\hline
\end{tabular}

Note: Each ranking is from best to worst and "Est." denotes the estimate; Omega ranking entails a combination of the downside and upside ranking. Investment options with "-“ estimates represents occurrences where the forecast returns exhibited no downside risk, making the estimation of scaled Sharpe ratios impossible.

Note: Barclays African Group (BGA), FirstRand Limited (FSR), Investec Limited (INL), Nedbank Group Limited (NED), the Standard Bank Group Limited (SBK), African Bank Investments Limited (ABL), Capitec Bank Holdings Limited (CPI), Grindrod Limited (GND), Sasfin Holdings Limited (SFN), the JSE Bank index (J835), the JSE Financial index (J580), the JSE All Share index (J203), the Dow Jones, the S\&P 500, the CAC 40, the DAX, the FTSE 100 index (UKX), the Nikkei 225 index (NI225), and the Shanghai Composite index (SHCOMP) are evaluated.

Source: The data were obtained from Yahoo Finance (2014) for the world indices and from the McGregor BFA (2014) database for the South African indices and shares. 
Table D: Risk-Adjusted Performance Rankings Based On The 24-Month Out-Of-Sample Forecast

\begin{tabular}{|c|c|c|c|c|c|c|c|c|c|c|c|c|}
\hline \multicolumn{13}{|c|}{ RANKINGS BASED ON 24-MONTH FORECAST (SEPTEMBER 2014 TO AUGUST 2016) } \\
\hline \multicolumn{2}{|c|}{ Traditional Sharpe } & \multicolumn{2}{|c|}{ SC Sharpe } & \multicolumn{2}{|c|}{ Sharpe $\mathbf{S}^{*}$} & \multicolumn{2}{|c|}{ SC Sharpe S* } & \multicolumn{2}{|c|}{ Sharpe $\mathrm{S}^{* *}$} & \multicolumn{2}{|c|}{ SC Sharpe $\mathbf{S}^{* *}$} & \multirow{2}{*}{$\begin{array}{c}\text { Omega } \\
\text { Rank }\end{array}$} \\
\hline Rank & Est. & Rank & Est. & Rank & Est. & Rank & Est. & Rank & Est. & Rank & Est. & \\
\hline S\&P 500 & $>5$ & S\&P 500 & $>5$ & S\&P 500 & - & S\&P 500 & - & S\&P 500 & - & S\&P 500 & - & FSR \\
\hline Dow Jones & $>5$ & Dow Jones & $>5$ & SFN & -0.02 & SFN & -0.02 & Dow Jones & $>5$ & Dow Jones & $>5$ & BGA \\
\hline INL & $>5$ & INL & $>5$ & SHCOMP & -0.07 & SHCOMP & -0.07 & INL & $>5$ & INL & $>5$ & J835 \\
\hline NI225 & $>5$ & NI225 & $>5$ & NED & -0.08 & NED & -0.08 & $\mathrm{~J} 203$ & $>5$ & J203 & $>5$ & NED \\
\hline FSR & $>5$ & FSR & $>5$ & J835 & -0.08 & J835 & -0.08 & NI225 & $>5$ & NI225 & $>5$ & CAC 40 \\
\hline J580 & $>5$ & J580 & $>5$ & SBK & -0.10 & SBK & -0.10 & UKX & $>5$ & UKX & $>5$ & SFN \\
\hline UKX & $>5$ & UKX & $>5$ & NI225 & -0.10 & NI225 & -0.10 & J580 & $>5$ & J580 & $>5$ & NI225 \\
\hline SFN & $>5$ & SFN & $>5$ & FSR & -0.10 & FSR & -0.10 & GND & $>5$ & GND & $>5$ & SHCOMP \\
\hline J203 & $>5$ & J203 & $>5$ & CPI & -0.10 & CPI & -0.10 & CAC 40 & $>5$ & CAC 40 & $>5$ & DAX \\
\hline J835 & $>5$ & J835 & $>5$ & DAX & -0.10 & DAX & -0.10 & DAX & $>5$ & DAX & $>5$ & SBK \\
\hline GND & $>5$ & GND & $>5$ & UKX & -0.10 & UKX & -0.10 & FSR & $>5$ & FSR & $>5$ & INL \\
\hline DAX & $>5$ & DAX & $>5$ & GND & -0.12 & GND & -0.12 & SHCOMP & $>5$ & SHCOMP & $>5$ & GND \\
\hline CAC 40 & $>5$ & CAC 40 & $>5$ & CAC 40 & -0.12 & CAC 40 & -0.12 & NED & $>5$ & NED & $>5$ & UKX \\
\hline NED & 4.86 & NED & 4.86 & INL & -0.13 & INL & -0.13 & J835 & $>5$ & J835 & $>5$ & CPI \\
\hline SBK & 3.86 & SBK & 3.86 & J580 & -0.13 & J580 & -0.13 & SBK & $>5$ & SBK & $>5$ & $\mathrm{~J} 203$ \\
\hline SHCOMP & 3.11 & SHCOMP & 3.11 & $\mathrm{~J} 203$ & -0.13 & $\mathrm{~J} 203$ & -0.13 & BGA & $>5$ & BGA & $>5$ & Dow Jones \\
\hline BGA & 2.45 & BGA & 2.45 & BGA & -0.13 & BGA & -0.13 & SFN & 3.85 & SFN & 3.85 & S\&P 500 \\
\hline CPI & -1.35 & CPI & -1.35 & Dow Jones & -0.13 & Dow Jones & -0.13 & CPI & -4.91 & CPI & -4.91 & J580 \\
\hline
\end{tabular}

Note: Each ranking is from best to worst and "Est." denotes the estimate; Omega ranking entails a combination of the downside and upside ranking. Investment options with "_. estimates represents occurrences where the forecast returns exhibited no downside risk, making the estimation of scaled Sharpe ratios impossible.

Note: Barclays African Group (BGA), FirstRand Limited (FSR), Investec Limited (INL), Nedbank Group Limited (NED), the Standard Bank Group Limited (SBK), African Bank Investments Limited (ABL), Capitec Bank Holdings Limited (CPI), Grindrod Limited (GND), Sasfin Holdings Limited (SFN), the JSE Bank index (J835), the JSE Financial index (J580), the JSE All Share index (J203), the Dow Jones, the S\&P 500, the CAC 40, the DAX, the FTSE 100 index (UKX), the Nikkei 225 index (NI225), and the Shanghai Composite index (SHCOMP) are evaluated.

Source: The data were obtained from Yahoo Finance (2014) for the world indices and from the McGregor BFA (2014) database for the South African indices and shares. 


\section{NOTES}

